\section{OPEN ACCESS}

Edited by:

Hitoshi Ishida,

Kitasato University, Japan

Reviewed by:

Tsunehiko Higuchi,

Nagoya City University, Japan

Masakazu Hirotsu,

Kanagawa University, Japan

*Correspondence:

Christiane Fernandes

chris@pq.cnpq.br

Adolfo Horn Jr.

adolfo@uenf.br

Specialty section:

This article was submitted to

Inorganic Chemistry,

a section of the journal

Frontiers in Chemistry

Received: 18 May 2018 Accepted: 26 September 2018 Published: 05 November 2018

Citation:

Costa RO, Ferreira SS, Pereira CA,

Harmer JR, Noble CJ, Schenk G,

Franco RWA, Resende JALC,

Comba P, Roberts AE, Fernandes $C$

and Horn A Jr (2018) A New

Mixed-Valence Mn(II)Mn(III)

Compound With Catalase and

Superoxide Dismutase Activities.

Front. Chem. 6:491.

doi: 10.3389/fchem.2018.00491

\title{
A New Mixed-Valence Mn(II)Mn(III) Compound With Catalase and Superoxide Dismutase Activities
}

\begin{abstract}
Rafael O. Costa ${ }^{1}$, Sarah S. Ferreira ${ }^{2}$, Crystiane A. Pereira ${ }^{1}$, Jeffrey R. Harmer ${ }^{3}$, Christopher J. Noble ${ }^{3}$, Gerhard Schenk ${ }^{4}$, Roberto W. A. Franco ${ }^{5}$, Jackson A. L. C. Resende ${ }^{6}$, Peter Comba ${ }^{7,8}$, Asha E. Roberts ${ }^{7,8}$, Christiane Fernandes ${ }^{1 *}$ and Adolfo Horn Jr. ${ }^{\text {* }}$

${ }^{1}$ Laboratório de Ciências Químicas, Universidade Estadual do Norte Fluminense Darcy Ribeiro, Campos dos Goytacazes, Brazil, ${ }^{2}$ Instituto Federal Fluminese, Campos dos Goytacazes, Brazil, ${ }^{3}$ Centre for Advanced Imaging, University of Queensland, Brisbane, QLD, Australia, ${ }^{4}$ School of Chemistry and Molecular Biosciences, University of Queensland, Brisbane, QLD, Australia, ${ }^{5}$ Laboratório de Ciências Físicas, Universidade Estadual do Norte Fluminense Darcy Ribeiro, Campos dos Goytacazes, Brazil, ${ }^{6}$ Instituto de Ciências Exatas e da Terra, Campus Universitário do Araguaia, Universidade Federal do Mato Grosso, Barra do Garças, Brazil, ${ }^{7}$ Anorganisch-Chemisches Institut, Universität Heidelberg, Heidelberg, Germany, ${ }^{8}$ Interdisziplinäres Zentrum für Wissenschaftliches Rechnen, Heidelberg, Germany
\end{abstract}

The synthesis, X-ray molecular structure, physico-chemical characterization and dual antioxidant activity (catalase and superoxide dismutase) of a new polymeric mixed valence $\mathrm{Mn}\left(\mathrm{III)} \mathrm{Mn}(\mathrm{II})\right.$ complex, containing the ligand $\mathrm{H}_{2} \mathrm{BPCINOL}(\mathrm{N}-(2-$ hydroxybenzyl)-N-(2-pyridylmethyl)[(3-chloro)(2-hydroxy)] propylamine) is described. The monomeric unit is composed of a dinuclear $\mathrm{Mn}(\mathrm{II}) \mathrm{Mn}(\mathrm{III})$ moiety, $[\mathrm{Mn}(\mathrm{III})(\mu$ $\mathrm{HBPCINOL})(\mu-\mathrm{BPCINOL}) \mathrm{Mn}(\mathrm{II})(\mathrm{Cl})]\left(\mathrm{ClO}_{4}\right) \cdot 2 \mathrm{H}_{2} \mathrm{O}, \mathbf{1}$, in which the $\mathrm{Mn}$ ions are connected by two different bridging groups provided by two molecules of the ligand $\mathrm{H}_{2} \mathrm{BPCINOL}$, a phenoxide and an alkoxide group. In the solid state, this mixed valence dinuclear unit is connected to its neighbors through chloro bridges. Magnetic measurements indicated the presence of ferromagnetic $\left[J=+0.076(13) \mathrm{cm}^{-1}\right]$ and antiferromagnetic $\left[J=-5.224(13) \mathrm{cm}^{-1}\right]$ interactions. The compound promotes $\mathrm{O}_{2}^{\bullet-}$ dismutation in aqueous solution $\left(\mathrm{IC}_{50}=0.370 \mu \mathrm{mol} \mathrm{dm}{ }^{-3}, k_{\text {cat }}=3.6 \times 10^{6} \mathrm{M}^{-1} \mathrm{~s}^{-1}\right)$. EPR studies revealed that a high-valent $\mathrm{Mn}(\mathrm{III})-\mathrm{O}-\mathrm{Mn}(\mathrm{IV})$ species is involved in the superoxide dismutation catalytic cycle. Complex $\mathbf{1}$ shows catalase activity only in the presence of a base, e.g., piperazine or triethylamine. Kinetic studies were carried out in the presence of piperazine and employing two different methods, resulting in $k_{\text {cat }}$ values of $0.58 \pm$ $0.03 \mathrm{~s}^{-1}$ (detection of $\mathrm{O}_{2}$ production employing a Clark electrode) and $2.59 \pm 0.12$ $\mathrm{S}^{-1}\left(\mathrm{H}_{2} \mathrm{O}_{2}\right.$ consuption recorded via UV-Vis). EPR and ESI-(+)-MS studies indicate that piperazine induces the oxidation of $\mathbf{1}$, resulting in the formation of the catalytically active $\mathrm{Mn}(\mathrm{III})-\mathrm{O}-\mathrm{Mn}(\mathrm{IV})$ species.

Keywords: catalase, superoxide dismutase, tripodal ligand, mix-valent manganese, polymeric manganese, reaction mechanism 


\section{INTRODUCTION}

The best described and studied forms of reactive oxygen species (ROS) are the superoxide anion $\left(\mathrm{O}_{2}^{\bullet-}\right)$ and hydrogen peroxide $\left(\mathrm{H}_{2} \mathrm{O}_{2}\right)$, which can produce the extremely reactive hydroxyl radical $\left(\mathrm{HO}^{\bullet}\right)$. Although performing key roles in biochemical processes such as the cell signaling, gene expression, and immune response, these oxidants also induce damage on cellular constituents, causing DNA, protein and lipid oxidation (Hancock et al., 2001; Halliwell, 2006; Morano et al., 2012). The uncontrolled generation of ROS has been related to many pathologies, including neurodegenerative disorders (Alzheimer's disease, amyotrophic lateral sclerosis, etc.) and is also thought to have an important action in the aging progression (Lane, 2003; McCord and Edeas, 2005; Valko et al., 2007).

Complex organisms such as human beings are able to coexist with free radicals and have established pathways to employ such ROS as oxidation/reduction switches, in a process known as redox signaling (Allen and Tresini, 2000; Lane, 2003). Hence, a certain level of oxidation performed by free radicals is required in biosystems, but increased oxidative levels may result in damages to the normal functioning of biological systems, resulting in pathophysiological conditions.

As a protection stratagem to counter the deleterious properties of ROS, aerobic organisms have developed antioxidant metalloenzymes, e.g., glutathione peroxidase (GPx), catalases (CATs), and superoxide dismutases (SODs) (Costa and MoradasFerreira, 2001; Valko et al., 2007). Whereas GPx and CATs act on $\mathrm{H}_{2} \mathrm{O}_{2}$, SODs induce superoxide dismutation. GPx contains selenium in the active site (Lu and Holmgren, 2009) while CATs possess an iron(III) heme prostetic cofactor or a dinuclear manganese active site (Bravo et al., 1999; Antonyuk et al., 2000). In SODs, iron, manganese, copper/zinc or nickel have been reported at the active site (Tainer et al., 1982; Ludwig et al., 1991; Kerfeld et al., 2003; Barondeau et al., 2004). SOD is assumed to be the main mediator to control the damaging effects of the superoxide anion in vivo. However, several practical restrictions (large size, low cell permeability, short circulating half-life, antigenicity, high manufacturing costs) have restricted the usage of SODs as a possible clinical treatment (McCord and Edeas, 2005).

An alternative to the use of antioxidant metalloenzymes to decrease the level of ROS is the development of synthetic compounds which may mimic the activity of such enzymes (Mahammed and Gross, 2011). Several biomimetics that can decompose ROS produced during oxidative stress (e.g., using metal ion ligands such as salen, porphyrins, corroles, or nonaromatic macrocycles) have already been reported (Doctrow et al., 2002; Day, 2007; Eckshtain et al., 2009; Batinić-Haberle et al., 2010; Kupershmidt et al., 2010; Tovmasyan et al., 2015; Weekley et al., 2017; Signorella et al., 2018).

Previously, we have described the synthesis of a tripodal tetradentade ligand HPCINOL = 1-(bispyridin-2-ylmethylamino)-3-chloropropan-2-ol (Horn et al., 2005a) and studied its coordination behavior with manganese(II) salts (Figure 1) (Lessa et al., 2007; Ribeiro et al., 2015). Their antioxidant properties have been also evaluated as a model for SOD and/or CAT enzymes (Lessa et al., 2009; Ribeiro et al., 2015). In an attempt to develop new and more active compounds with SOD/CAT activities, we employed a similar tripodal tetradentate ligand, i.e., $\mathrm{H}_{2} \mathrm{BPClNOL}=\mathrm{N}$-(2-hydroxybenzyl)-N-(2-pyridylmethyl) [(3chloro)(2-hydroxy)] propylamine (Figure 1) (Horn et al., 2000), for the synthesis of a related manganese compound. Here, we present the properties of the new and rare polymeric mixed valence $\mathrm{Mn}(\mathrm{II}) \mathrm{Mn}$ (III) complex and the evaluation of its kinetic properties and mechanism of action with respect to its SOD and CAT mimetic activities.

\section{EXPERIMENTAL SECTION}

\section{Materials and Methods}

All chemicals and reagents were purchased from Sigma-Aldrich and used as such. UV-Vis, EPR, and MS investigations were carried out employing spectroscopic, HPLC or MS quality solvents. Dimethylsulfoxide (DMSO) was distilled over drying agents under an inert atmosphere, prior to EPR studies. It was stored over drying agents under inert atmosphere and transferred by syringe.

\section{Physical Chemical Characterization}

Infrared spectra were recorded on a Shimadzu FT-IR 8300 spectrophotometer. The solid sample was prepared in a $\mathrm{KBr}$ pellet and the spectrum were recorded over the frequency range of $400-4,000 \mathrm{~cm}^{-1}$. UV-Vis spectra for the ligand and for the $\mathrm{Mn}$ complex were recorded in $\mathrm{CH}_{3} \mathrm{CN}$ on a UV-Vis Varian Cary 50 Bio spectrophotometer. The electrical conductivity of a $1 \times$ $10^{-3} \mathrm{~mol} \mathrm{dm}{ }^{-3} \mathrm{CH}_{3} \mathrm{CN}$ solution of $\mathbf{1}$ was measured with a Biocristal conductometer. Melting points were measured on a Microquimica MQAPF-301 apparatus. The purity of the complex was determined by combustion elemental analyses conducted with a Thermo Scientific FLASH 2000 CHNS/O analyzer. Full scan mass spectra were obtained on a MicroTOF LC Bruker Daltonics spectrometer equipped with an electrospray source operating in positive ion mode. Samples were dissolved in a $\mathrm{CH}_{3} \mathrm{CN} / \mathrm{H}_{2} \mathrm{O}(50 / 50)$ solution and were injected in the apparatus by direct infusion. Theoretical isotopic patterns were calculated using the software ESI Compass 1.3 for micrOTOF, DataAnalysis version 4.0 SP 1 from Bruker Daltonik GmbH. EPR spectra were recorded on a Bruker Elexsys E500 EPR spectrometer equipped with a Bruker ER036TM Teslameter and frequency counter for calibration of the magnetic field and microwave frequency, respectively. Low temperature $(140 \mathrm{~K})$ at the sample position employed a nitrogen flow-through system in conjunction with a liquid nitrogen Eurotherm ER4131vt temperature controller. Computer simulation of the dimanganese EPR spectra employed Molecular Sophe28 in conjunction with Octave29 to optimize the spin Hamiltonian parameters. The magnetic data were collected using an MPMS-XL 5T (Quantum Design) SQUID magnetometer. Sample preparation involved pressing the powder into PTFE tape to prevent field-induced reorientation. Data were corrected for diamagnetic contributions from the sample using Pascal's constants, and from the sample holder. Effective magnetic moments were calculated using the relationship $\mu_{\mathrm{eff}}=2.828\left(\chi_{\mathrm{M}} \mathrm{T}\right)^{1 / 2}$. 


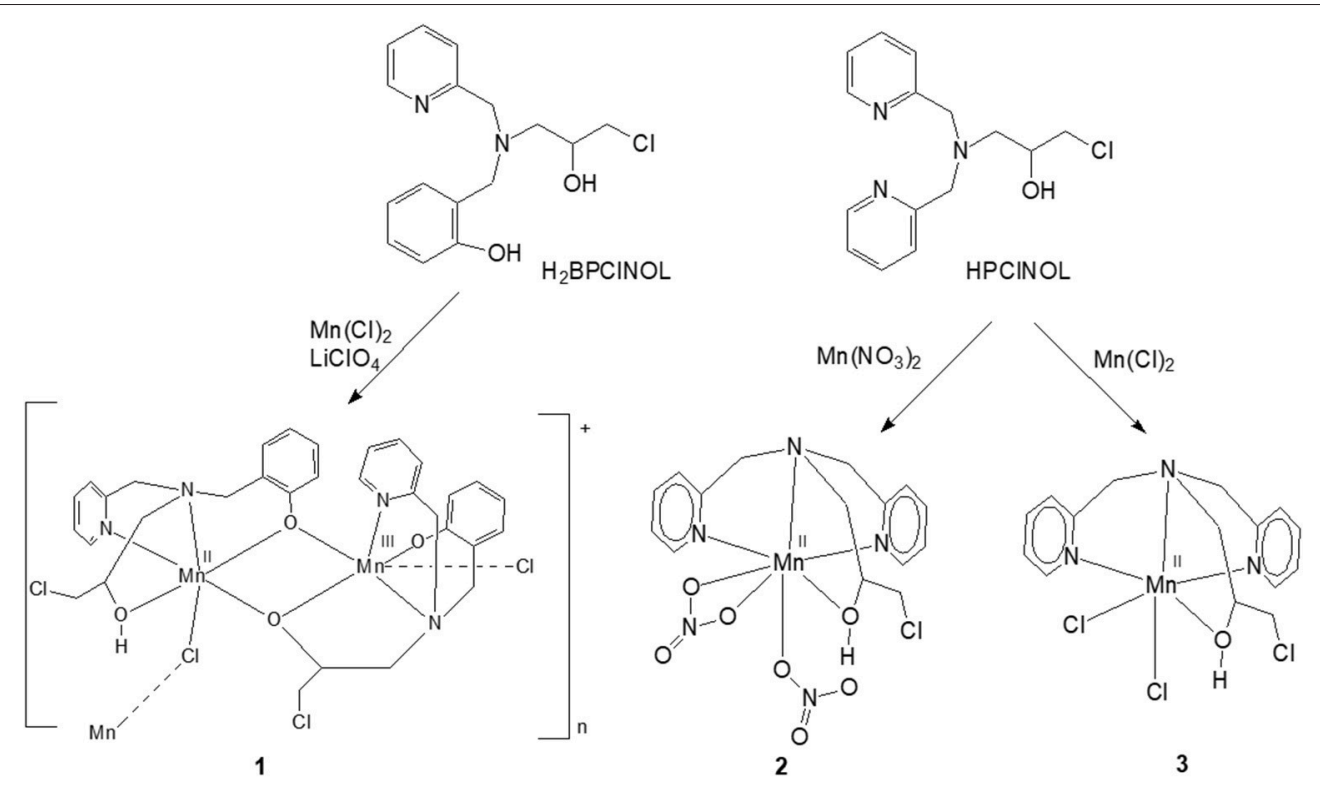

FIGURE 1 | Scheme of synthesis of $\mathbf{1}$ and the related manganese complexes $\mathbf{2}$ and $\mathbf{3}$ described previously by our group; both have SOD/CAT activities. Only the monomeric unit of the cation $\mathbf{1}$ is shown (Lessa et al., 2007, 2009; Ribeiro et al., 2015).

\section{Ligand and Complex Syntheses}

The ligand $\mathrm{H}_{2} \mathrm{BPCINOL}$ was synthesized by a reaction between the secondary amine $\mathrm{N}$-(2-hydroxybenzyl)-N(pyridin-2-ylmethyl)amine (HBPA) and epichlorohydrin, as reported previously (Horn et al., 2000). The complex $\left([(\mathrm{HBPClNOL}) \mathrm{Mn}(\mathrm{II}) \mathrm{Mn}(\mathrm{III})(\mathrm{BPClNOL})(\mathrm{Cl})]\left(\mathrm{ClO}_{4}\right) \cdot 2 \mathrm{H}_{2} \mathrm{O}\right)_{\mathrm{n}}$,

1 (Figure 1), was prepared in a reaction between $\mathrm{H}_{2} \mathrm{BPClNOL}$ $(1.0 \mathrm{mmol}, 0.31 \mathrm{~g})$, dissolved in $10 \mathrm{~cm}^{3}$ of propan-2-ol and a solution containing $\mathrm{MnCl}_{2} \cdot 4 \mathrm{H}_{2} \mathrm{O}(1.0 \mathrm{mmol}, 0.20 \mathrm{~g})$ and $\mathrm{LiClO}_{4}(1 \mathrm{mmol}, 0.11 \mathrm{~g})$, by refluxing over $1 \mathrm{~h}$. After allowing the brown solution to stand for a few days, a crystalline brown solid was filtered off, washed with ethyl ether and dried under vacuum. After removing the crystals, the slow evaporation of the solvent resulted in the formation of an unidentified oily material. Yield: $0.20 \mathrm{~g}$ (22\%). m.p. $243^{\circ} \mathrm{C}$. IR $\left(\mathrm{cm}^{-1}\right): v(\mathrm{OH}), 3422-3483(\mathrm{~s}) ; \mathrm{v}(\mathrm{CH}), 3,067$ and 3,030 (s); $v\left(\mathrm{CH}_{2}\right), 2,969(\mathrm{~s}) ; \nu\left(\mathrm{CH}_{2}\right), 2,924(\mathrm{~s}) ;(\mathrm{C}=\mathrm{C}$ and $\mathrm{C}=\mathrm{N})$, 1,601 (s), 1,574 (s), $1,478(\mathrm{~s})$ and $1,456(\mathrm{~s}) ; \mathrm{v}\left(\mathrm{ClO}_{4}^{-}\right), 1,121$ and $1,020(\mathrm{~s}) ; \gamma(\mathrm{CH}), 758(\mathrm{~s})$ and $775(\mathrm{~s})$. Anal. calcd for $[(\mathrm{HBPClNOL}) \mathrm{Mn}(\mathrm{II}) \mathrm{Mn}(\mathrm{III})(\mathrm{BPClNOL})(\mathrm{Cl})]\left(\mathrm{ClO}_{4}\right) 2 \mathrm{H}_{2} \mathrm{O}$ $\left(\mathrm{C}_{32} \mathrm{H}_{39} \mathrm{Cl}_{4} \mathrm{Mn}_{2} \mathrm{~N}_{4} \mathrm{O}_{10}, \mathrm{MW}=891.37 \mathrm{~g} \mathrm{~mol}^{-1}\right): \mathrm{C}, 43.12 ; \mathrm{H}$, 4.41; N, 6.29. Found: C, 42.77; H, 4.01; N, 5.92\%. $\Omega=123 \mu \mathrm{S}$ $\mathrm{cm}^{-1}$ (1:1 electrolyte, $\left.\mathrm{CH}_{3} \mathrm{CN}\right)$.

\section{X-Ray Crystallography}

The single crystal X-ray diffraction data of complex $\mathbf{1}$ were collected at $150(2) \mathrm{K}$ on a Bruker D8 Venture diffractometer equipped with Photon $100 \mathrm{CMOS}$ detector and using $\mathrm{MoK} \alpha$ radiation $(0.71073 \AA)$ from an INCOATEC micro-focus source. Final lattice parameter values and integrated intensities were obtained using SAINT software (SAINT, 2015), and a multi-scan absorption correction was applied with SADABS (Krause et al.,
2015). The structure was solved by direct methods using intrinsic phasing implemented in SHELXT (Sheldrick, 2015). The model was refined applying the full-matrix least-squares method using SHELXL (Sheldrick, 2015). All non-hydrogen atoms were refined with anisotropic displacement parameters. Hydrogen atoms were placed at calculated positions and refined using a riding model.

\section{Catalase-Like Activity}

Catalase activity was measured by employing two different methods: (i) the decrease of $\mathrm{H}_{2} \mathrm{O}_{2}$ concentration was followed by UV-Vis spectroscopy at $240 \mathrm{~nm}$ (Beers and Sizer, 1952), and (ii) the rate of $\mathrm{O}_{2}$ production was measured employing a Clark-type electrode from Hansatech Instruments, model Oxygraph+.

The concentration of the $\mathrm{H}_{2} \mathrm{O}_{2}$ was previously determined by iodide/thiosulfate titration according to the literature (Ribeiro et al., 2009). All the reactions between complex $\mathbf{1}$ and $\mathrm{H}_{2} \mathrm{O}_{2}$ were performed in buffered and unbuffered solutions, as well as in the presence of piperazine. For the studies in unbuffered water solutions, $0.2 \mathrm{~cm}^{3}$ of an aqueous solution of complex $1(2.5 \times$ $10^{-4} \mathrm{~mol} \mathrm{dm}^{-3}$ ) was added to a cuvette, followed by the addition of a certain amount (dependent on the required concentration) of water and $\mathrm{H}_{2} \mathrm{O}_{2}$ to reach a final volume of $2.2 \mathrm{~cm}^{3}$. Subsequently, the decrease in the absorption of the band attributed to $\mathrm{H}_{2} \mathrm{O}_{2}$ was monitored in a $1 \mathrm{~cm}$ path length cell. A similar study was performed using a buffered system (phosphate buffer, $0.05 \mathrm{~mol}$ $\mathrm{dm}^{-3}, \mathrm{pH} 7.8$ ). For the study with piperazine, $0.2 \mathrm{~cm}^{3}$ of an aqueous solution of complex $1\left(2.5 \times 10^{-4} \mathrm{~mol} \mathrm{dm}^{-3}\right)$ was added to a cuvette, followed by the addition of $0.1 \mathrm{~cm}^{3}$ of an aqueous solution of piperazine $\left(0.1 \mathrm{~mol} \mathrm{dm}^{-3}\right)$ and appropriate amounts of water and $\mathrm{H}_{2} \mathrm{O}_{2}$ to reach a final volume of $2.2 \mathrm{~cm}^{3}$. In this solution, the final concentration of 1 was $2.27 \times 10^{-5} \mathrm{~mol}$ $\mathrm{dm}^{-3}$, while that of the piperazine was $4.54 \times 10^{-3} \mathrm{~mol} \mathrm{dm}^{-3}$, 
with a resulting $\mathrm{pH}$ of 9.73 . The experiments were always carried out at $25^{\circ} \mathrm{C}$. The consumption of $\mathrm{H}_{2} \mathrm{O}_{2}$ was again monitored spectrophotometrically as described above. These measurements were performed in triplicates and the kinetic parameters (i.e., $\mathrm{K}_{\mathrm{M}}, \mathrm{k}_{\mathrm{cat}}, \mathrm{k}_{\mathrm{cat}} / \mathrm{K}_{\mathrm{M}}$ ) were determined from a fit of the data to the Michaelis-Menten equation. Using the Clark electrode, the $\mathrm{O}_{2}$ production was followed for $120 \mathrm{~s}$, but the rate of the reaction was measured during the first $50 \mathrm{~s}$. The concentrations of $\mathbf{1}$ and piperazine were the same as described for the UV-Vis experiments.

The reaction was also investigated by EPR. A fresh solution of 1 was prepared in $\mathrm{CH}_{3} \mathrm{CN}\left(1.10^{-3} \mathrm{~mol} \mathrm{dm}{ }^{-3}\right)$. From this solution $0.200 \mathrm{~cm}^{3}$ was placed in an EPR tube, which was then frozen at $140 \mathrm{~K}$ and the EPR spectrum recorded. The tube was then allowed to thaw at room temperature ( $\sim 15 \mathrm{~min})$. To this solution, in the EPR tube, $50 \mathrm{~mm}^{3}$ of an aqueous solution of piperazine $\left(0.1 \mathrm{~mol} \mathrm{dm}^{-3}\right)$ was added. The solution was frozen again and the EPR spectrum recorded. Subsequently, the sample was allowed to thaw again $(\sim 15 \mathrm{~min})$, and $50 \mathrm{~mm}^{3}$ of an aqueous solution of $\mathrm{H}_{2} \mathrm{O}_{2}\left(0.1 \mathrm{~mol} \mathrm{dm}^{-3}\right)$ was added. After freezing, another EPR spectrum was recorded. This study was repeated in duplicates.

All these experiments were carried out using crystalline samples that contains a mixture of two diastereomers (see x-ray section for more details).

\section{SOD-Like Activity}

The SOD activity of complex $\mathbf{1}$ was assessed employing the nitroblue tetrazolium (NBT) method, using xanthine/xanthine oxidase as a source of the superoxide anion, as described previously (Ribeiro et al., 2015). The kinetic studies were carried out in phosphate buffer $(\mathrm{pH}=7.8)$. Stock solutions of xanthine $\left(4.5 \times 10^{-4} \mathrm{~mol} \mathrm{dm}^{-3}\right)$, NBT $\left(5.6 \times 10^{-5} \mathrm{~mol} \mathrm{dm}^{-3}\right)$ and xanthine oxidase $\left(0.2 \mathrm{U} \mathrm{cm}^{-3}\right)$, all purchased from SigmaAldrich, were prepared using phosphate buffer. In a control (blank) experiment the stock solutions of xanthine $\left(1 \mathrm{~cm}^{3}\right)$ and NBT $\left(1 \mathrm{~cm}^{3}\right)$ were mixed with phosphate buffer $\left(0.4 \mathrm{~cm}^{3}\right)$, and, at the end, xanthine oxidase $\left(0.20 \mathrm{~cm}^{3}\right)$ was added to the cuvette. To evaluate the SOD activity of $\mathbf{1}$, different concentrations of the complex were added to the cuvette: $9.62 \times 10^{-8}, 1.92 \times 10^{-7}$, $3.85 \times 10^{-7}, 5.77 \times 10^{-7}$, and $7.69 \times 10^{-7} \mathrm{~mol} \mathrm{dm}^{-3}$.

The obtained $\mathrm{IC}_{50}$ was transformed to $\mathrm{k}_{\mathrm{cat}}$ employing the equation proposed by McCord and Fridovich, $\mathrm{k}_{\mathrm{cat}}=\mathrm{k}_{\mathrm{NBT}} \mathrm{x}$ $[\mathrm{NBT}] / \mathrm{IC}_{50}$, where $\mathrm{K}_{\mathrm{NBT}}=5.94 \times 10^{4} \mathrm{M}^{-1} \mathrm{~s}^{-1}$ (Grau et al., 2014; Ledesma et al., 2015).

The SOD like activity of $\mathbf{1}$ was also studied by EPR. A solution containing superoxide anion radical was generated in DMSO using the procedure described previously (Valentine et al., 1984). Briefly, $7 \mathrm{mg}$ of $\mathrm{KO}_{2}$ was stirred in $1 \mathrm{~cm}^{3}$ of dried DMSO, for $2 \mathrm{~h}$, resulting in a pale yellow solution $\left(0.1 \mathrm{~mol} \mathrm{dm}^{-3}\right)$. A fresh solution of 1 was prepared in dried DMSO $\left(1.6 \times 10^{-3} \mathrm{~mol}\right.$ $\left.\mathrm{dm}^{-3}\right)$, resulting in a brown solution. The $\mathrm{KO}_{2}$ solution $(0.200$ $\mathrm{cm}^{3}$ ) was placed in an EPR tube and the solution frozen and the spectrum recorded. The tube was removed from the cavity and allowed to sit at room temperature until a pale yellow solution was obtained again. Then, $200 \mu \mathrm{L}$ of the solution of complex 1 was added to the former, resulting in a color change from pale yellow to reddish brown. The solution was frozen and the spectrum recorded. To follow the changes in the intensity of the superoxide EPR signal, the tube was removed from the cavity and allowed to thaw at room temperature; this was repeated until no more changes in the intensity of the spectrum were observed. This study was repeated in duplicate. As a control, a similar reaction was carried out using a $\mathrm{MnCl}_{2} \cdot 4 \mathrm{H}_{2} \mathrm{O}$ solution $(1.6 \times$ $10^{-3} \mathrm{~mol} \mathrm{dm}^{-3}$ ).

All these experiments were carried out using crystalline samples that contain a mixture of two diastereomers (see $\mathrm{x}$-ray section for more details).

\section{RESULTS AND DISCUSSION}

\section{Syntheses}

The ligand $\mathrm{H}_{2} \mathrm{BPClNOL}$ is a tripodal ligand with a $\mathrm{N}_{2} \mathrm{O}_{2}$ donor atom set and is able to form mono- and dinuclear complexes with different metal ions, including iron, nickel, copper and zinc (see below for more details about these complexes). Here, we report the first manganese complex obtained with this ligand. The reaction between $\mathrm{H}_{2} \mathrm{BPClNOL}$ and $\mathrm{MnCl}_{2} \cdot 4 \mathrm{H}_{2} \mathrm{O}$ resulted in a

TABLE 1 | Crystal data and structure refinement details for complex 1.

\begin{tabular}{|c|c|}
\hline $\begin{array}{l}\text { Empirical } \\
\text { formula }\end{array}$ & {$\left[\mathrm{Mn}_{2}\left(\mathrm{C}_{16} \mathrm{H}_{17} \mathrm{CIN}_{2} \mathrm{O}_{2}\right)\left(\mathrm{C}_{16} \mathrm{H}_{18} \mathrm{ClN}_{2} \mathrm{O}_{2}\right) \mathrm{Cl}\right] \mathrm{ClO}_{4} \cdot 1.67\left(\mathrm{H}_{2} \mathrm{O}\right)$} \\
\hline Formula weight & 891.35 \\
\hline Temperature/K & 150.15 \\
\hline Crystal system & Monoclinic \\
\hline Space group & $\mathrm{P} 22_{1} / \mathrm{n}$ \\
\hline$a / \AA ̊$ & $14.2991(15)$ \\
\hline$b / \AA$ & $12.4755(12)$ \\
\hline$c / \AA ̊$ & 21.676(2) \\
\hline$\alpha / /^{\circ}$ & 90 \\
\hline$\beta /{ }^{\circ}$ & $103.558(5)$ \\
\hline$\gamma /{ }^{\circ}$ & 90 \\
\hline Volume $/ \AA^{3}$ & $3759.0(7)$ \\
\hline Z & 4 \\
\hline$\rho_{\text {calc }} \mathrm{g} / \mathrm{cm}^{3}$ & 1.575 \\
\hline$\mu / \mathrm{mm}^{-1}$ & 1.016 \\
\hline$F(000)$ & 1828.0 \\
\hline Crystal size $/ \mathrm{mm}^{3}$ & $0.29 \times 0.137 \times 0.115$ \\
\hline Radiation & $\operatorname{MoK} \alpha(\lambda=0.71073)$ \\
\hline 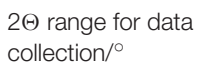 & 4.388 to 50.7 \\
\hline Index ranges & $-17 \leq h \leq 16,-14 \leq k \leq 15,-17 \leq \mathrm{I} \leq 26$ \\
\hline $\begin{array}{l}\text { Reflections } \\
\text { collected }\end{array}$ & 24450 \\
\hline $\begin{array}{l}\text { Independent } \\
\text { reflections }\end{array}$ & $6847\left[R_{\text {int }}=0.0958, R_{\text {sigma }}=0.1010\right]$ \\
\hline $\begin{array}{l}\text { Data/restraints/ } \\
\text { parameters }\end{array}$ & $6847 / 19 / 498$ \\
\hline $\begin{array}{l}\text { Goodness-of-fit on } \\
\mathrm{F}^{2}\end{array}$ & 1.023 \\
\hline $\begin{array}{l}\text { Final } R \text { indexes }[1 \\
\geq 2 \sigma(I)]\end{array}$ & $R_{1}=0.0753, w R_{2}=0.1747$ \\
\hline $\begin{array}{l}\text { Final } R \text { indexes [all } \\
\text { data] }\end{array}$ & $R_{1}=0.1271, w R_{2}=0.2087$ \\
\hline $\begin{array}{l}\text { Largest diff. } \\
\text { peak/hole / e } \AA^{-3}\end{array}$ & $0.99 /-1.11$ \\
\hline
\end{tabular}


new compound that was isolated in the form of brownish crystals suitable for X-ray diffraction. The X-ray data have revealed (see below) the presence of an unusual, one dimensional mixedvalence $\mathrm{Mn}$ (II)Mn(III) chain. The elemental analysis agrees with the X-ray data, indicating high purity of the prepared compound. This complex is stable in air, in the solid state and in $\mathrm{CH}_{3} \mathrm{CN}$ solution. Its solution shows a brownish color, suggesting the presence of manganese in oxidation state higher than +2 . This indicates that $\mathrm{H}_{2} \mathrm{BPClNOL}$ shows a different behavior when compared with HPCINOL, which forms mononuclear Mn(II) complexes (Figure 1).

\section{X-Ray Molecular Structure}

The molecular structure of $\mathbf{1}$ was solved by X-ray diffraction and the crystallographic data are presented in Tables 1 and 2. The data reveal the formation of a chain (Figure 2), where each subunit contains a heterovalent dimanganese (II/III) core, two molecules of the ligand and one chloro ligand, resulting in the composition $[\mathrm{Mn}(\mathrm{II}) \mathrm{Mn}(\mathrm{III})(\mathrm{HBPClNOL})(\mathrm{BPClNOL}) \mathrm{Cl}]^{+}$, where $\mathrm{HBPCINOL}$ and BPCINOL stand for the mono- and dianionic form of $\mathrm{H}_{2} \mathrm{BPClNOL}$, respectively. The monomers are connected through chloro bridges, which are asymmetrically bound to the manganese centers $[\mathrm{Mn} 1-\mathrm{Cl} 1=2.4908$ (17), $\left.\mathrm{Mn} 2-\mathrm{Cl}_{\mathrm{i}}=2.6162(18) \AA\right]$. As shown in Figure 1, the ligand $\mathrm{H}_{2} \mathrm{BPClNOL}$ has two oxygen (phenol and alcohol) and two nitrogen (pyridine and tertiary amine) atoms as coordinating groups; interesting is the fact that the two molecules of the

TABLE 2 | Selected bonds distances (Å) and angles (deg) for complex 1.

\begin{tabular}{|c|c|c|c|}
\hline Mn1-O1A & $2.249(4)$ & $\mathrm{Mn} 2-\mathrm{O} 1 \mathrm{~B}$ & $1.892(5)$ \\
\hline $\mathrm{Mn} 1-\mathrm{O} 2 \mathrm{~A}$ & $2.201(5)$ & $\mathrm{Mn} 2-\mathrm{O} 2 \mathrm{~B}$ & $1.899(4)$ \\
\hline $\mathrm{Mn} 1-\mathrm{N} 1 \mathrm{~A}$ & $2.240(5)$ & $\mathrm{Mn} 2-\mathrm{N} 1 \mathrm{~B}$ & $2.263(5)$ \\
\hline $\mathrm{Mn} 1-\mathrm{N} 2 \mathrm{~A}$ & $2.314(5)$ & $\mathrm{Mn} 2-\mathrm{N} 2 \mathrm{~B}$ & $2.073(5)$ \\
\hline $\mathrm{Mn1}-\mathrm{O} 2 \mathrm{~B}$ & $2.129(4)$ & $\mathrm{Mn} 2-\mathrm{O} 1 \mathrm{~A}$ & $1.934(4)$ \\
\hline $\mathrm{Mn} 1-\mathrm{Cl} 1$ & $2.4908(17)$ & $\mathrm{Mn} 2-\mathrm{Cl}_{1}^{(i)}$ & $2.6162(18)$ \\
\hline Mn1-Mn2 & $3.1593(14)$ & & \\
\hline $\mathrm{O} 2 \mathrm{~B}-\mathrm{Mn} 1-\mathrm{O} 2 \mathrm{~A}$ & $95.50(17)$ & $\mathrm{O} 1 \mathrm{~B}-\mathrm{Mn} 2-\mathrm{O} 2 \mathrm{~B}$ & $172.81(17)$ \\
\hline $\mathrm{O} 2 \mathrm{~B}-\mathrm{Mn} 1-\mathrm{N} 1 \mathrm{~A}$ & 153.49(19) & $\mathrm{O} 1 \mathrm{~B}-\mathrm{Mn} 2-\mathrm{O} 1 \mathrm{~A}$ & $103.45(18)$ \\
\hline $\mathrm{O} 2 \mathrm{~A}-\mathrm{Mn} 1-\mathrm{N} 1 \mathrm{~A}$ & 111.01(19) & $\mathrm{O} 2 \mathrm{~B}-\mathrm{Mn} 2-\mathrm{O} 1 \mathrm{~A}$ & $82.53(17)$ \\
\hline $\mathrm{O} 2 \mathrm{~B}-\mathrm{Mn} 1-\mathrm{O} 1 \mathrm{~A}$ & $70.50(14)$ & $\mathrm{O} 1 \mathrm{~B}-\mathrm{Mn} 2-\mathrm{N} 2 \mathrm{~B}$ & 93.3(2) \\
\hline $\mathrm{O} 2 \mathrm{~A}-\mathrm{Mn} 1-\mathrm{O} 1 \mathrm{~A}$ & 148.14(17) & $\mathrm{O} 2 \mathrm{~B}-\mathrm{Mn} 2-\mathrm{N} 2 \mathrm{~B}$ & $81.9(2)$ \\
\hline $\mathrm{N} 1 \mathrm{~A}-\mathrm{Mn1}-\mathrm{O} 1 \mathrm{~A}$ & $86.07(17)$ & $\mathrm{O} 1 \mathrm{~A}-\mathrm{Mn} 2-\mathrm{N} 2 \mathrm{~B}$ & 158.3(2) \\
\hline $\mathrm{O} 2 \mathrm{~B}-\mathrm{Mn} 1-\mathrm{N} 2 \mathrm{~A}$ & 112.75(18) & $\mathrm{O} 1 \mathrm{~B}-\mathrm{Mn} 2-\mathrm{N} 1 \mathrm{~B}$ & $87.18(19)$ \\
\hline $\mathrm{O} 2 \mathrm{~A}-\mathrm{Mn} 1-\mathrm{N} 2 \mathrm{~A}$ & $75.43(18)$ & $\mathrm{O} 2 \mathrm{~B}-\mathrm{Mn} 2-\mathrm{N} 1 \mathrm{~B}$ & $97.12(19)$ \\
\hline $\mathrm{N} 1 \mathrm{~A}-\mathrm{Mn} 1-\mathrm{N} 2 \mathrm{~A}$ & $75.44(19)$ & $\mathrm{O} 1 \mathrm{~A}-\mathrm{Mn} 2-\mathrm{N} 1 \mathrm{~B}$ & 87.82(18) \\
\hline $\mathrm{O} 1 \mathrm{~A}-\mathrm{Mn} 1-\mathrm{N} 2 \mathrm{~A}$ & $83.74(18)$ & $\mathrm{N} 2 \mathrm{~B}-\mathrm{Mn} 2-\mathrm{N} 1 \mathrm{~B}$ & 79.22(19) \\
\hline $\mathrm{O} 2 \mathrm{~B}-\mathrm{Mn} 1-\mathrm{Cl} 1$ & $88.78(12)$ & $\mathrm{O} 1 \mathrm{~B}-\mathrm{Mn} 2-\mathrm{Cl}^{(i)}$ & $87.15(14)$ \\
\hline $\mathrm{O} 2 \mathrm{~A}-\mathrm{Mn} 1-\mathrm{Cl} 1$ & $85.96(13)$ & $\mathrm{O} 2 \mathrm{~B}-\mathrm{Mn} 2-\mathrm{Cl}^{(i)}$ & $88.45(14)$ \\
\hline $\mathrm{N} 1 \mathrm{~A}-\mathrm{Mn} 1-\mathrm{Cl} 1$ & $93.05(15)$ & $\mathrm{O} 1 \mathrm{~A}-\mathrm{Mn} 2-\mathrm{Cl}^{(i)}$ & $94.21(14)$ \\
\hline $\mathrm{O} 1 \mathrm{~A}-\mathrm{Mn} 1-\mathrm{Cl} 1$ & 120.95(13) & $\mathrm{N} 2 \mathrm{~B}-\mathrm{Mn} 2-\mathrm{Cl}^{(1)}$ & $100.39(15)$ \\
\hline $\mathrm{N} 2 \mathrm{~A}-\mathrm{Mn} 1-\mathrm{Cl} 1$ & $152.45(15)$ & $\mathrm{N} 1 \mathrm{~B}-\mathrm{Mn} 2-\mathrm{Cl}^{(i)}$ & 174.28(15) \\
\hline $\mathrm{Mn} 1-\mathrm{O} 1 \mathrm{~A}-\mathrm{Mn} 2$ & $97.84(2)$ & $\mathrm{Mn} 1-\mathrm{O} 2 \mathrm{~B}-\mathrm{Mn} 2$ & $103.21(2)$ \\
\hline
\end{tabular}

Symmetry codes: (i) $-x+3 / 2, y-1 / 2,-z+1 / 2$; (ii) $-x+3 / 2, y+1 / 2,-z+1 / 2$ ligand coordinate differently to the metal centers, mainly with respect to their phenol and alcohol groups (see Figure 1). For a better explanation of the molecular structure of complex 1, we label the two molecules of the ligand present in this complex as $\mathrm{A}$ and $\mathrm{B}$ in the $\mathrm{X}$-ray structure representation (Figure 2). Ligand A (monoanion) shows a tetradentate coordination mode in which the phenol is acting as a bridging group [Mn1$\mathrm{O} 1 \mathrm{~A}=2.249(4)$ and $\mathrm{Mn} 2-\mathrm{O} 1 \mathrm{~A}=1.934(4) \AA]$ and the alcohol group is protonated and acts as a terminal ligand $[\mathrm{Mn} 1-\mathrm{O} 2 \mathrm{~A}=$ 2.201(5) $\AA$ ]. On the other hand, in ligand $\mathrm{B}$ (dianion), the alcohol is deprotonated and acting as a bridging group [Mn2O2B = 1.899(4), Mn1-O2B = 2.129(4) $]$, while the phenol group is deprotonated as well but coordinating as a non-bridging ligand only to Mn2 [Mn2-O1B = 1.892(5) $\mathrm{A}]$. Furthermore, the carbon atom of the alcohol group is chiral and two isomers are present in the compound. In ligand $\mathrm{A}$, the $\mathrm{R}$ isomer is observed, while the $\mathrm{S}$ isomer is seen in ligand $\mathrm{B}$. It is important to note that compound $\mathbf{1}$ crystallizes in the centrosymmetric space group $\mathrm{P} 21 / \mathrm{n}$. Due to the relation of symmetry associated with this space group, the crystal also shows molecules in which the isomers are opposite to those observed in the molecule shown in Figure 2. Molecules showing two chiral centers can form four diastereomers, which can be identified as RR, SS, $\mathrm{RS}$, and SR. The x-ray data revealed that only two of them were formed, the RS and SR. Although the RR and SS were foreseen, they were not present in the crystals evaluated by $\mathrm{x}$-ray analyses, even when the crystals were obtained from different syntheses. It is possible that the RR and SS diatereomers did not crystallize togheter with the RS and SR species, since they can result in compounds with different solubility, or that the dinuclear species are not formed due to steric hindrance. This can be one reason to explain the low yield observed in the synthesis. We hope to address this behavior in a future work.

The averaged bond lengths around the two metal ions are 2.27 and 2.11 $\AA$ for the Mn1 and Mn2 ions, respectively. Based on (i) the bond distances, (ii) the fact that the Mn(III) ion has a smaller ionic radius than $\mathrm{Mn}(\mathrm{II})$ (Gelasco et al., 1997; Singh et al., 2015), (iii) the asymmetric coordination of the bridging chloride, and (iv) the fact that the dianionic form of $\mathrm{H}_{2} \mathrm{BPClNOL}$ is a harder Lewis base than the monoanionic one, it is plausible to assume that $\mathrm{Mn} 1$ and $\mathrm{Mn} 2$ are in the +2 and +3 oxidation states, respectively. Furthermore, the Mn1-Cl1 bond lengths are similar to those observed in other complexes containing Mn(II)-Cl bonds (2.425-2.472 ) (Reddig et al., 2004). The Mn*Mn distance is 3.1593(14) $\AA$, which is significantly shorter than the distances observed for a series of dinuclear $\mathrm{Mn}(\mathrm{II})$ complexes containing derivatives of the ligand 2 -\{[bis(pyridin-2-ylmethyl)amino]-methyl $\}$ phenol [3.392(8) to 3.493(2) ̊] (Reddig et al., 2004). Furthermore, for a family of complexes containing the ligand 1,3-bis(salicylideneamino)-2propanol, with which dinuclear $\mathrm{Mn}(\mathrm{II}) \mathrm{Mn}(\mathrm{II}), \mathrm{Mn}(\mathrm{II}) \mathrm{Mn}(\mathrm{III})$, $\mathrm{Mn}(\mathrm{III}) \mathrm{Mn}(\mathrm{III})$ and $\mathrm{Mn}(\mathrm{III}) \mathrm{Mn}(\mathrm{IV})$ complexes with di- $\mu$ alkoxide bridges were generated, the $\mathrm{Mn}^{\cdots}{ }^{\cdots} \mathrm{Mn}$ distance is in the range between 3.25 and $3.33 \AA$ (Gelasco et al., 1997). 


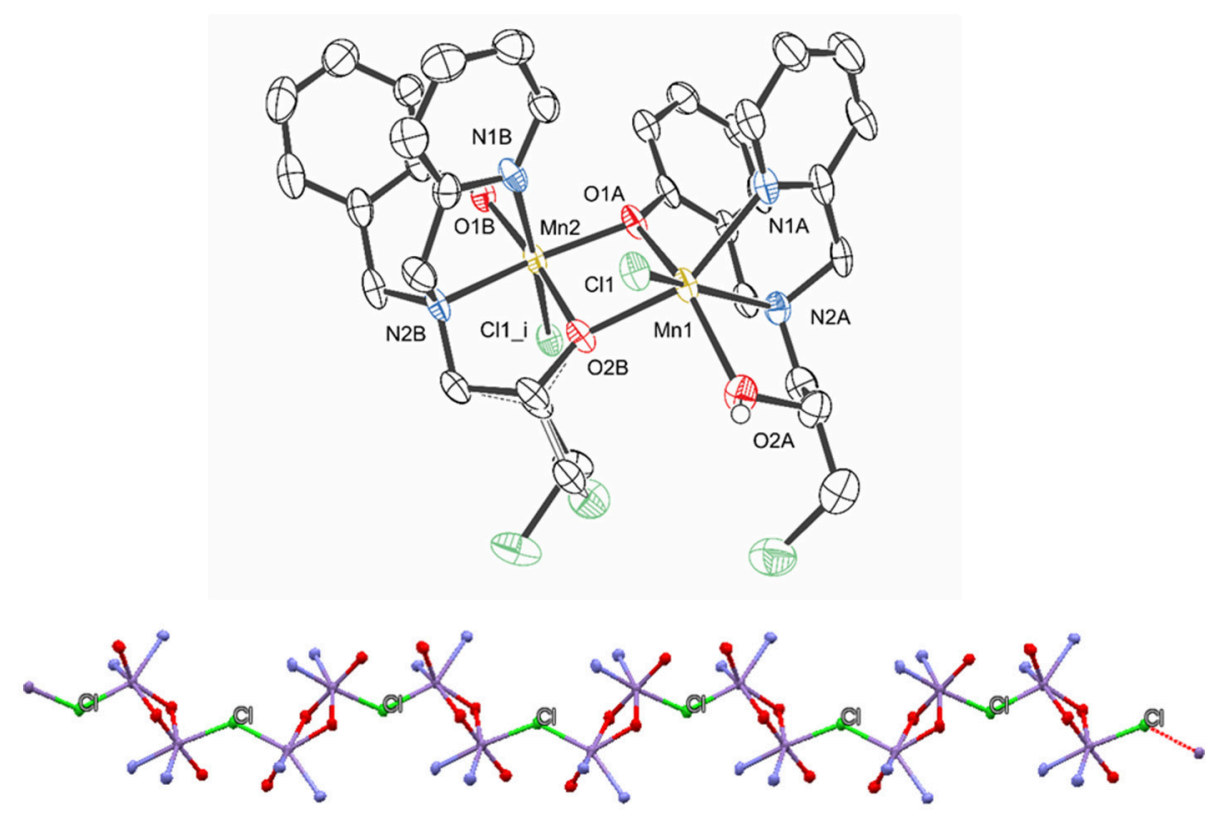

FIGURE 2 | Structure representation of compound $\mathbf{1}$ (hydrogen atoms, perchlorate anion, and water of crystallyzation were omitted for clarity) (Top) and view of the polymeric chain (Bottom), highlighting the chloro bridges that connect the monomers (only the atoms coordinated to the manganese centers are shown for clarity). The ellipsoids are drawn at $50 \%$ probability.

Several structures containing $\mathrm{H}_{2} \mathrm{BPCINOL}$ and other metal ions have been described in the literature. This ligand forms a dinuclear complex with $\mathrm{Cu}(\mathrm{II})$, containing di-chloro bridges. However, mononuclear $\mathrm{Cu}(\mathrm{II}), \mathrm{Zn}$ (II), and $\mathrm{Fe}(\mathrm{III})$ complexes have also been observed (Fernandes et al., 2010; Gomes et al., 2017). Interestingly, in the presence of $\mathrm{Ni}$ (II), a dinuclear species containing two phenoxide bridges was formed (Horn et al., 2006a), while the structures of three diiron(III) complexes demonstrate the presence of alkoxide bridges (Horn et al., 2005b, 2006b). In contrast, the mixed valence $+2 /+3$ dinuclear $\mathrm{Mn}$ species described here has mixed bridging groups (alkoxide and phenoxide moieties). It appears that the oxidation state of the metal ions is a determining factor for the identity of the bridging groups [i.e., oxidation statedependent isomerism (Mitić et al., 2003)]. Thus, the homovalent $+3 /+3$ (iron complexes) and $+2 /+2$ (nickel complex) systems have dialkoxide and diphenoxide bridges, respectively, while the heterovalent $+2 /+3$ systems have an alkoxide and a phenoxide bridge.

\section{Infrared, UV-VIS, ESI-(+)-MS, and EPR Characterization}

The IR spectrum of the Mn(III)Mn(II) complex 1 was recorded and compared with that of its free ligand $\mathrm{H}_{2} \mathrm{BPCINOL}$ in the region between 4,000 and $400 \mathrm{~cm}^{-1}$. For $\mathrm{H}_{2} \mathrm{BPClNOL}$, characteristic bands of the aromatic group are observed at 1,595, $1,558,1,475$, and $1,433 \mathrm{~cm}^{-1}$, assigned to $\nu \mathrm{C}=\mathrm{N}$ and $\nu \mathrm{C}=\mathrm{C}$. For complex 1 , the corresponding bands are observed at 1,601, 1,574, 1,478 , and $1,456 \mathrm{~cm}^{-1} \cdot \mathrm{H}_{2} \mathrm{BPClNOL}$ also shows an intense band at $1,289 \mathrm{~cm}^{-1}$ that is attributed to $v \mathrm{C}-\mathrm{O}$ of the phenol group; the corresponding feature is observed at $1,275 \mathrm{~cm}^{-1}$ in complex $\mathbf{1}$.
Furthermore, 1 has two intense bands at 1,121 and $1,080 \mathrm{~cm}^{-1}$, which are associated with the perchlorate anion. These bands are absent in the spectrum of the ligand.

The electronic spectrum in acetonitrile of complex $\mathbf{1}$ is dominated by intense bands in the UV range: $238 \mathrm{~nm}(\varepsilon=1.8 \times$ $\left.10^{4} \mathrm{dm}^{3} \mathrm{~mol}^{-1} \mathrm{~cm}^{-1}\right), 262 \mathrm{~nm}\left(\varepsilon=1.5 \times 10^{4} \mathrm{dm}^{3} \mathrm{~mol}^{-1} \mathrm{~cm}^{-1}\right)$, $316 \mathrm{~nm}\left(\varepsilon=4.7 \times 10^{4} \mathrm{dm}^{3} \mathrm{~mol}^{-1} \mathrm{~cm}^{-1}\right)$ and $364 \mathrm{~nm}(\varepsilon=3.3 \times$ $\left.10^{4} \mathrm{dm}^{3} \mathrm{~mol}^{-1} \mathrm{~cm}^{-1}\right)$. In the Vis range, a shoulder is observed at $459 \mathrm{~nm}\left(3.0 \times 10^{3} \mathrm{dm}^{3} \mathrm{~mol}^{-1} \mathrm{~cm}^{-1}\right)$. While the UV bands are attributed to $\pi \rightarrow \pi^{*}$ intraligand transitions, the lower energy transition is assigned to a phenolate $\rightarrow \mathrm{Mn}^{\text {III }}$ LMCT transition (Karsten et al., 2002; Singh et al., 2015).

The analysis of a solution containing complex $\mathbf{1}$ by ESI(+)-MS indicated the presence of peaks with $\mathrm{m} / \mathrm{z}$ of 201 , $307,359,377,419,665,718,735,754$, and 763. The peaks at $\mathrm{m} / \mathrm{z} 307$ and 201 are ascribed to the protonated form of the ligand and to its fragment, respectively. The peak at $\mathrm{m} / z 665$ is ascribed to a mononuclear cation containing two molecules of $\mathrm{H}_{2} \mathrm{BPCINOL}$ (herewith referred to as $\mathrm{H}_{2} \mathrm{~L}$ ): $\left[\mathrm{Mn}(\mathrm{III})(\mathrm{HL})_{2}\right]^{+}$. The peaks with $m / z 718,735,754$ and 763 are ascribed to $\left[\mathrm{Mn}(\mathrm{III}) \mathrm{Mn}(\mathrm{II})(\mathrm{L})_{2}\right]^{+},\left[\mathrm{Mn}_{2}(\mathrm{III})(\mathrm{L})_{2}(\mathrm{OH})\right]^{+}$, $[\mathrm{Mn}(\mathrm{III}) \mathrm{Mn}(\mathrm{II})(\mathrm{HL})(\mathrm{L})(\mathrm{Cl})]^{+}, \quad\left[\mathrm{Mn}_{2}(\mathrm{III})(\mathrm{L})_{2}(\mathrm{CN})\left(\mathrm{H}_{2} \mathrm{O}\right)\right]^{+}$, respectively. These proposed assignments are based on the comparison of the simulated and experimental isotopic pattern and on the MS/MS data for each peak (see Figures ESI1-9 in Supplementary Material). MS/MS data indicate that the cations with $m / z 763,754$, and 735 yield the cation with $m / z 718$, which corresponds to a dinuclear $\mathrm{Mn}$ (III)Mn(II) arrangement, in agreement with the data obtained from $x$-ray diffraction. It should be pointed out that the species with $m / z 718$ and the one with $m / z 754$ both agree with the presence of mixed valence Mn 
centers. In particular, the species associated with $\mathrm{m} / \mathrm{z} 754$ is in perfect agreement with the molecular structure observed for the monomeric unit, as revealed by x-ray diffraction. A proposal for the structure of the main signals observed in the ESI-(+)-MS study is presented as suplementary information.

Due to the novelty of the mixed-valent, mixed-bridged and polymeric structure of $\mathbf{1}$ in the solid state, the effect of $\mathrm{CH}_{3} \mathrm{CN}$, DMSO, and $\mathrm{H}_{2} \mathrm{O}$ on the molecular arrangement was investigated by EPR at $1.8 \mathrm{~K}$ (Figure ESI10) and $140 \mathrm{~K}$ (Figure 3) in order to probe if solvents promote structural changes. While the spectra recorded in $\mathrm{H}_{2} \mathrm{O}$ and DMSO are similar, they differ significantly from the spectrum in $\mathrm{CH}_{3} \mathrm{CN}$, indicating that the solvent has a considerable effect on the structure of the compound.

In the solid state, compound $\mathbf{1}$ shows only one broad band around $\mathrm{g}=2$ (see Figure ESI10), but when measured in a $\mathrm{CH}_{3} \mathrm{CN}$ solution a six-line signal at $\mathrm{g} \sim 2$, which is characteristic of $\mathrm{Mn}(\mathrm{II})$ ions, and a broad band at $\mathrm{g} \sim 7$ are observed, indicating a significant change in the magnetic behavior of the system after solubilization. Broad resonances at low field have been previously described for coupled $\mathrm{Mn}$ (II)Mn(III) systems, and were interpreted in terms of the presence of ferro- or antiferromagnetically coupled $\mathrm{Mn}$ (II)Mn(III) cores. A feature of this low field signal is that for an antiferromagnetically coupled system, the signal disappears when the temperature decreases (Smith et al., 2009). On the other hand, in ferromagneticallycoupled $\mathrm{Mn}(\mathrm{II}) \mathrm{Mn}(\mathrm{III})$ dimers, the signal grows at low temperatures (Gelasco et al., 1997). We have observed that the signal around $\mathrm{g} \sim 7$ increases upon lowering the temperature from $140 \mathrm{~K}$ to $1.8 \mathrm{~K}$ (Figure ESI11), which indicates that complex 1 contains a ferromagnetically-coupled $\mathrm{Mn}$ (II)Mn(III) dimer. This interpretation was further confirmed by magnetic measurements (see below). In addition, in $\mathrm{Mn}$ (II)Mn(III) systems with antiferromagnetic coupling, multiline features with as many as 36 lines can be observed around $\mathrm{g}=2$ due to the population of the $S=1 / 2$ state of the dinuclear manganese

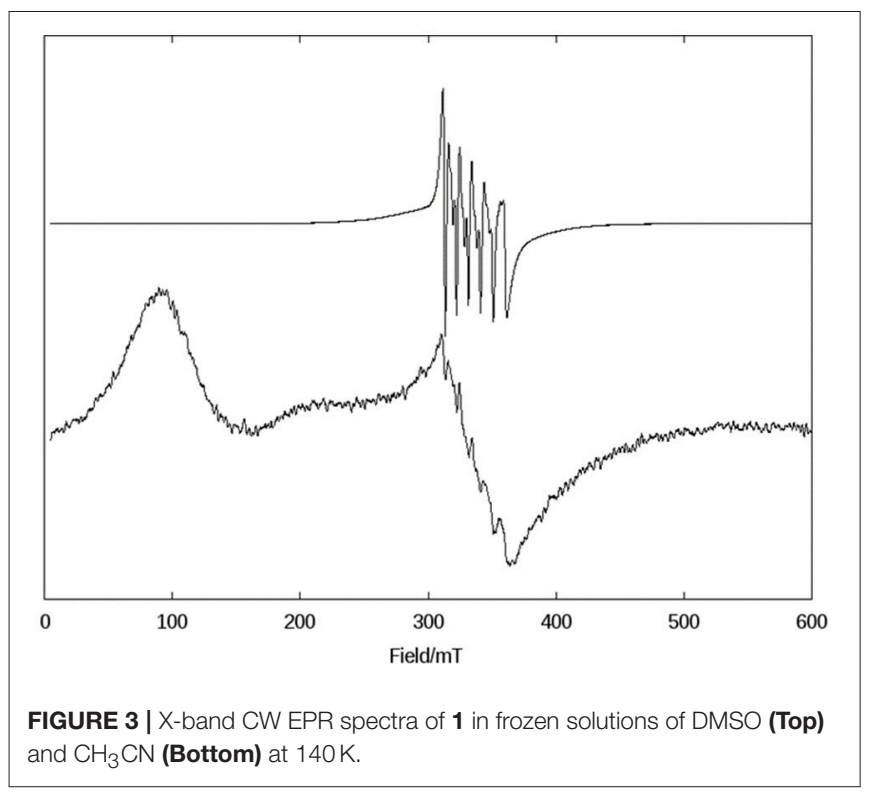

system (Smith et al., 2009; Sano et al., 2013; Jung and Rentschler, 2015; Magherusan et al., 2018). In contrast, for ferromagneticallycoupled $\mathrm{Mn}(\mathrm{II}) \mathrm{Mn}$ (III) complexes published EPR data vary, including compounds that only show a signal at low field ( $\mathrm{g}$ $>5$ ), or only a signal at high field ( $\mathrm{g} \sim 2$ ), or a combination of both features (Schake et al., 1991; Gelasco et al., 1997; Rane et al., 2000). Thus, the spectral features of compound $\mathbf{1}$ are in agreement with other ferromagnetically-coupled $\mathrm{Mn}$ (II)Mn(III) systems, and the difference between the spectra in the solid state and in the $\mathrm{CH}_{3} \mathrm{CN}$ solution is ascribed to the dissociation of the polymeric structure in solution, leaving the dinuclear antiferromagnetically-coupled $\mathrm{Mn}$ (II)Mn(III) system.

In DMSO (and $\mathrm{H}_{2} \mathrm{O}$ ) the EPR spectrum features six sharp lines (due to a ${ }^{55} \mathrm{Mn}$ hyperfine intetraction, $I=5 / 2$ ), typical of an isolated $\mathrm{Mn}$ (II) species and very similar to those obtained for the mononuclear complex [Mn(II)(HPClNOL) $\left(\mathrm{NO}_{3}\right)_{2}$ ], 2 (Figure 1) (Lessa et al., 2009). HPCINOL is similar to $\mathrm{H}_{2} \mathrm{BPClNOL}$, the ligand employed in this study, but has two pyridine groups instead of one pyridine and one phenol group (Figure 1). The same behavior was observed in aqueous solution. This observation suggests that the dinuclear structure of the monomer is not stable in DMSO and water and, therefore, only the six-line signal typical of isolated $\mathrm{Mn}$ (II) centers was observed (Lessa et al., 2009). In contrast, in acetonitrile, the dimeric structure is stable, resulting in a decrease in resolution and intensity of the features associated with the $\mathrm{Mn}(\mathrm{II})$ center.

\section{Magnetism}

The magnetic susceptibility of complex 1 was measured over the temperature range $2-300 \mathrm{~K}$ at $0.05 \mathrm{~T}$. The experimental data are presented as a $\chi_{\mathrm{M}} \mathrm{T}$ vs. T plot (Figure 4) of the $\mathrm{Mn}^{\mathrm{II}} \mathrm{Mn}^{\mathrm{III}}$ dinuclear unit.

The room temperature value of $7.20 \mathrm{~cm}^{3} \mathrm{~mol}^{-1} \mathrm{~K}$ ( $\mu=7.59 \mathrm{BM}$ ) is slightly lower than the theoretical value for two non-interacting spin systems of $7.38 \mathrm{~cm}^{3} \mathrm{~mol}^{-1} \mathrm{~K}$ $\left(\mu=7.68 \mathrm{BM} g=2, S_{\mathrm{A}}=5 / 2, S_{\mathrm{B}}=2\right)$. The susceptibility steadily decreases with decreasing temperature, indicating antiferromagnetic interactions between the two metal centers. The low temperature value of $1.32 \mathrm{~cm}^{3} \mathrm{~mol}^{-1} \mathrm{~K}(\mu=3.25 \mathrm{BM})$ is higher than the low temperature limit $\left(\chi_{\mathrm{M}} \mathrm{T}=0.38 \mathrm{~cm}^{3} \mathrm{~mol}^{-1}\right.$ $\mathrm{K}, \mu=1.73 \mathrm{BM} g=2, S=1 / 2$ ) of an antiferromagnetically coupled system of this kind. In a simple dinuclear complex, this would indicate the presence of mononuclear impurities, however, the X-ray crystal structure indicates that the dinuclear $\mathrm{Mn}^{\mathrm{II}}(\mu$ $\mathrm{OR})_{2} \mathrm{Mn}^{\mathrm{III}}$ units are bridged by a chloride ion to form a one dimesion chain. The compound thus has a chain structure with alternating $S=2: S=5 / 2$ spin carriers and $(\mu-\mathrm{OR})_{2}: \mu-\mathrm{Cl}$ interaction pathways. For this reason, attempts to fit the data for a single coupling constant were unsatisfactory, and we considered the Heisenberg chain Hamiltonian instead. The spin Hamiltonian in zero field is:

$$
\mathbf{H}=-J \sum_{i} \mathbf{S}_{B_{i}}\left[(1+\alpha) \mathbf{S}_{A_{i}}+(1-\alpha) \mathbf{S}_{A_{i+1}}\right]
$$

The derivation of the function for an alternating ferromagnetic chain compound was described by Pei (Pei et al., 1988), where 


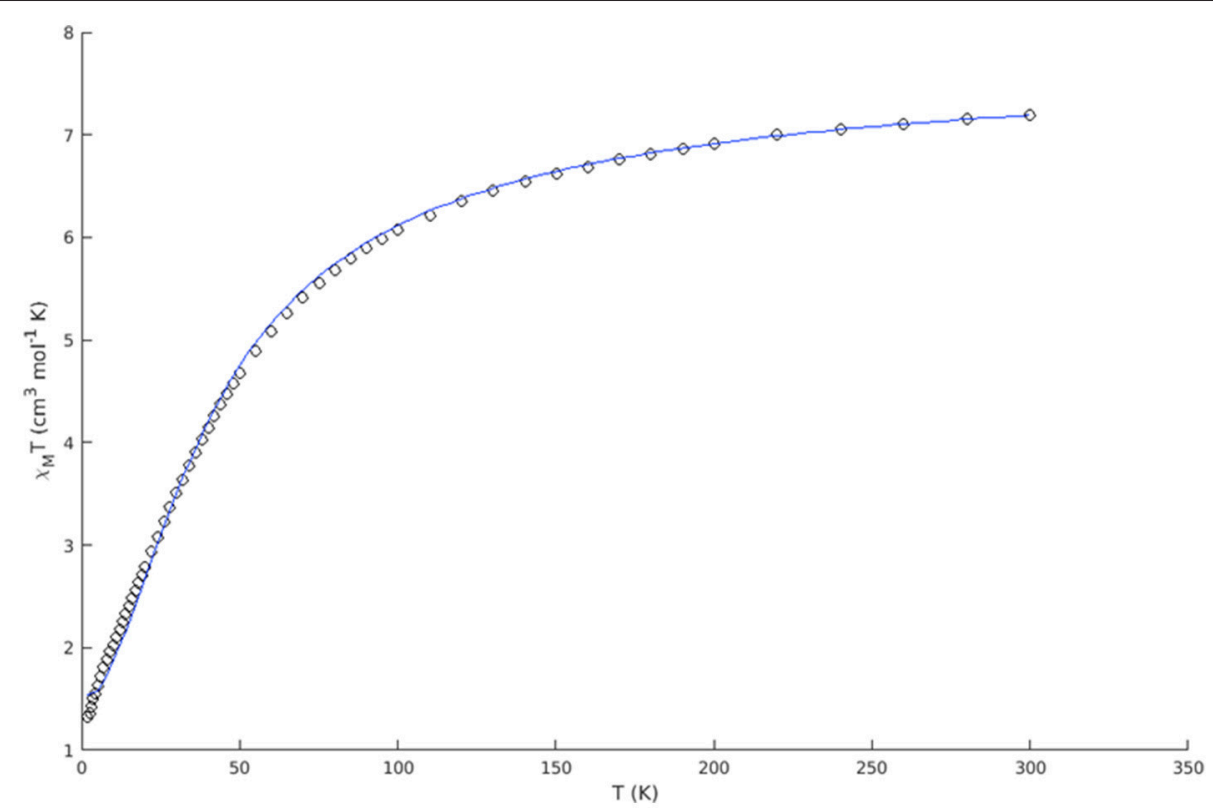

FIGURE 4 | Experimental $\chi_{M}^{\top}$ vs. T plot of complex $\mathbf{1}$ (open circles) and best fit (blue solid line).

$\chi_{\mathrm{M}} \mathrm{T}$ is defined as:

$\chi_{M} T=\frac{N \beta^{2}}{3 k} \frac{g^{2}[s(s+1)(1-P)+2 Q R]+2 g G(Q+R)+G^{2}(1+P)}{1-P}$

with

$G=g_{A}\left[S_{A}\left(S_{A}+1\right)\right]^{1 / 2} g=g_{B} s=S_{B} x=J / k T$

$$
P=\frac{A_{1}}{A_{0}}
$$$$
Q=\frac{x\left[(1+\alpha) B_{0}+(1-\alpha) B_{1}\right]}{A_{0}}
$$$$
R=\frac{x\left[(1-\alpha) B_{0}+(1+\alpha) B_{1}\right]}{A_{0}}
$$$$
A_{0}=\frac{2 \pi}{\Lambda^{2}} \sum_{\sigma=-s}^{s} \sum_{\varepsilon= \pm} \frac{\varepsilon \exp \left(\sigma \lambda_{\varepsilon}\right)}{\sigma^{2}}\left(\sigma \lambda_{\varepsilon}-1\right)
$$$$
A_{1}=\frac{\pi}{\Lambda^{2}} \sum_{\sigma=-s}^{s} \sum_{\varepsilon= \pm} \frac{\varepsilon \exp \left(\sigma \lambda_{\varepsilon}\right)}{\sigma^{4}}\left[\sigma^{3} \lambda_{\varepsilon}^{3}-3 \sigma^{2} \lambda_{\varepsilon}^{2}\right.
$$$$
\left.+\left(6-\sigma^{2} \lambda^{2}\right) \sigma \lambda_{\varepsilon}+\sigma^{2} \lambda^{2}-6\right]
$$$$
B_{0}=\frac{2 \pi}{\Lambda^{2}} \sum_{\sigma=-s}^{s} \sum_{\varepsilon= \pm} \varepsilon \exp \left(\sigma \lambda_{\varepsilon}\right)
$$$$
B_{1}=\frac{\pi}{\Lambda^{2}} \sum_{\sigma=-s}^{s} \sum_{\varepsilon= \pm} \frac{\varepsilon \exp \left(\sigma \lambda_{\varepsilon}\right)}{\sigma^{2}}\left[\sigma^{2} \lambda_{\varepsilon}^{2}-2 \sigma \lambda_{\varepsilon}+2-\sigma^{2} \lambda^{2}\right]
$$

$\lambda_{+}=-2 x \lambda_{-}=\alpha \lambda_{+} \lambda^{2}=2 x^{2}\left(1+\alpha^{2}\right) \Lambda^{2}=x^{2}\left(1+\alpha^{2}\right)$

with $g_{\mathrm{A}}=g_{\mathrm{B}}=2.05, S_{\mathrm{A}}=5 / 2$ and $S_{\mathrm{B}}=2$. The data were fit for $\alpha$ and $J$, where $J$ is defined as:

$$
J=J_{A B}\left[S_{A}\left(S_{A}+1\right)\right]^{1 / 2}
$$

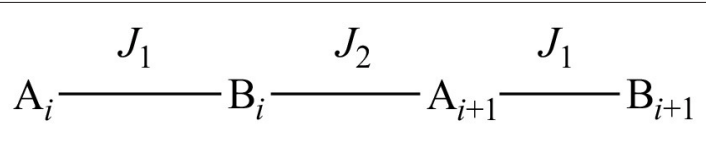

SCHEME 1 | A representation of the exchange coupling constants $\left(J_{1}\right.$ and $\left.J_{2}\right)$ of an alternating ferrimagnetic chain complex; $A$ and $B$ represent the two different spin carriers.

The two different coupling pathways $\left(J_{1}\right.$ and $\left.J_{2}\right)$ are represented in Scheme 1 and the coupling constants are then given by:

$$
J_{1}=J_{A B}(1+\alpha) \quad J_{2}=J_{A B}(1-\alpha)
$$

The best fit gave $\alpha=1.029(2)$ and $J=-7.614(40) \mathrm{cm}^{-1}$, resulting in two exchange coupling constants of $J_{1}=-5.224(13)$ and $J_{2}=+0.076(13) \mathrm{cm}^{-1}$. The antiferromagnetic coupling $\left(J_{1}\right)$ is ascribed to the interaction via the chloro bridge, where the more linear $\mathrm{M}-\mathrm{Cl}-\mathrm{M}$ angle of $129.34^{\circ}$ is expected to facilitate antiferromagnetic interactions (Orchard, 2003). This conclusion is in agreement with other similar chloro bridged complexes $(\mathrm{Fu}$ et al., 1996; Gibson et al., 2003; Coates et al., 2010; Hirotsu et al., 2012; Zou et al., 2012).

The very weak ferromagnetic coupling $\left(J_{2}\right)$ is attributed to exchange via the di-OR bridge. The Mn-OR-Mn angles were found to be $97.84^{\circ}$ and $103.21^{\circ}$, with a Mn-O-O-Mn torsion angle of $156.56^{\circ}$, which is consistent with ferromagnetic exchange (Gelasco et al., 1997; Wittick et al., 2004; Naiya et al., 2012; Hänninen et al., 2013). Similar structural features have also been observed in a set of di- and trinuclear mixed valence manganese complexes (Hänninen et al., 2013). The ferromagnetic coupling constants of the dinuclear complexes were found in the range 
of $+2.15(6)$ to $+7.9(7) \mathrm{cm}^{-1}$, whereas a much smaller coupling constant of $+0.04(7) \mathrm{cm}^{-1}$ was observed in the case of one of the trinuclear complexes. The smaller value of $J$ was attributed to a shift of the central $\mathrm{Mn}^{\mathrm{II}}$ ion out of the plane of the bridging oxygens, reducing the ferromagnetic contribution to the coupling between the $\mathrm{d} x y$ and $\mathrm{d} x^{2}-y^{2}$ orbitals. This distortion is not observed in the present case, and the small ferromagnetic coupling likely stems from the slightly elongated Mn-OR bond lengths of complex 1 (1.897-2.250 $\AA$, average $2.052 \AA$ ) when compared to the reported dinuclear complexes (1.889-1.934 $\AA$, average $1.912 \AA$ ).

The confirmation of the presence of ferromagnetic coupling involving the $\mathrm{Mn}(\mathrm{II})-(\mu-\mathrm{OR})_{2}-\mathrm{Mn}$ (III) explains the behavior of the signal seen at $g \sim 7$ in the EPR spectrum, which does not disappear when the temperature drops from 140 to $1.8 \mathrm{~K}$.

\section{Superoxide Dismutase (SOD) Activity}

The SOD-like activity of complex $\mathbf{1}$ was studied employing the NBT assay in aqueous buffered solution ( $\mathrm{pH}$ 7.8). NBT is a compound that undergoes reduction in the presence of superoxide anions, resulting in a purple species that may be monitored at $560 \mathrm{~nm}$. The superoxide anions are generated at a constant rate by the xanthine/xanthine oxidase system (O'Connor et al., 2012). In this assay, the capability of the compound of interest (i.e., 1) to prevent NBT reduction is evaluated. Thus, the concentration of the compound that inhibits $50 \%$ of NBT reduction corresponds to the $\mathrm{IC}_{50}$. As a control we determined that the pure ligand was not active. Relevant results are summarized in Table 3, together with corresponding data for other compounds, including the native SOD enzymes. The kinetic parameters $\left(\mathrm{IC}_{50}\right.$ and $k_{\text {cat }}$ ) related to the SOD-like activity of complex $\mathbf{1}$ are similar to those of complex 3 reported by us previously (see Table 3 ), and are in the same range observed for other manganese compounds.

Attempts to evaluate the interaction between an aqueous solution of $\mathbf{1}$ and the superoxide anion produced by the xanthine/xanthine oxidase system by EPR, as published previously (dojindo.com) $)^{1}$, were unsuccessful. Therefore, although the SOD activity of $\mathbf{1}$ was measured in a buffered aqueous solution, we carried out an EPR investigation of the reaction in DMSO. In this context it is important to highlight that the EPR spectrum of $\mathbf{1}$ in water and in DMSO are identical, revealing the presence of mononuclear species.

A DMSO solution of $\mathrm{KO}_{2}$ shows an anisotropic EPR spectrum $\left(\mathrm{g}_{/ /}=2.11\right.$ and $\left.\mathrm{g}_{\perp}=2.01\right)$ characteristic of $\mathrm{O}_{2}^{\bullet-}$ (Figure 5A) (Valentine et al., 1977). In dry DMSO the spectrum for complex 1 displays a six-line pattern, typical of isolated $\mathrm{Mn}$ (II) species as discussed above (Figures 3, 5B). Figure 5C shows the spectrum recorded immediately after the interaction between the superoxide anion and complex $\mathbf{1}$. In this case, a 16-line feature is observed, which was previously ascribed to a $\mathrm{Mn}$ (III) Mn(IV) dimer containing an oxo bridge (Dubois et al., 2008; Jiang et al., 2009; Mitić et al., 2009). The simulation of this 16-line spectrum is shown in Figure ESI12, and is in excellent agreement with the

${ }^{1}$ https://www.dojindo.com/Shared/Protocol/SpinTrapApplication.pdf Retrieved: 09/11/2017.
TABLE 3 | Kinetic parameters of reported manganese superoxide dismutase mimetics containing tripodal amine ligands and the natural enzyme.

\begin{tabular}{|c|c|c|c|}
\hline \multirow[t]{2}{*}{ Compound } & \multicolumn{2}{|c|}{ SOD Activity } & \multirow[t]{2}{*}{ References } \\
\hline & $I_{50}(\mu \mathrm{M})$ & $\begin{array}{c}10^{6} \mathrm{k}_{\mathrm{cat}} \\
\left(\mathrm{M}^{-1} \mathrm{~s}^{-1}\right)\end{array}$ & \\
\hline $1^{a}$ & $0.370 \pm 0.012$ & 3.4 & This work \\
\hline $3^{a}$ & $0.34 \pm 0.02$ & 3.7 & Ribeiro et al., 2015 \\
\hline$\left[\mathrm{Mn}(\mathrm{II})(\mathrm{TMIMA})_{2}\right]^{2+\mathrm{b}}$ & $1.6 \pm 0.1$ & 3.6 & Durot et al., 2005 \\
\hline$\left[\mathrm{Mn}(\mathrm{II})(\mathrm{BMPG})\left(\mathrm{H}_{2} \mathrm{O}\right)\right]^{+\mathrm{b}}$ & $1.2 \pm 0.5$ & 4.8 & Durot et al., 2005 \\
\hline$\left[\mathrm{Mn}(\mathrm{BIG})\left(\mathrm{H}_{2} \mathrm{O}\right)_{2}\right]^{+\mathrm{b}}$ & $3.7 \pm 0.6$ & 1.5 & Durot et al., 2005 \\
\hline$[\mathrm{Mn}(\mathrm{IPG})(\mathrm{MeOH})]^{+b}$ & $3.0 \pm 0.6$ & 1.9 & Durot et al., 2005 \\
\hline$\left[\mathrm{Mn}(\mathrm{PBMPA}) \mathrm{Cl}\left(\mathrm{H}_{2} \mathrm{O}\right)\right]^{a / b}$ & $2.67 \pm 0.37$ & 4.9 & Pap et al., 2012 \\
\hline CuZn-SODa & 0.03 & n.d & Weser et al., 1981 \\
\hline CuZn-SODC & 0.0026 & n.d & $\begin{array}{l}\text { Suksrichavalit } \\
\text { et al., } 2008\end{array}$ \\
\hline Human MnSODd & - & 800 & Ramilo et al., 1999 \\
\hline T. thermophiles ${ }^{\mathrm{e}}$ & - & 0.002 & Bull et al., 1991 \\
\hline
\end{tabular}

${ }^{a}$ study carried out with xanthine/xanthine oxidase-mediated reduction of NBT; ${ }^{b}$ study carried out with xanthine/xanthine oxidase-mediated reduction of cytochrome c; ${ }^{c}$ study carried out with xanthine/xanthine oxidase SOD assay kit-WST; ${ }^{d}$ pulse radiolysis;. ${ }^{e} \mathrm{KO}_{2}$. HPCINOL, 1-[bis(pyridin-2-ylmethyl)amino]-3-chloropropan-2-ol; TMIMA, tris[(1-methyl2-imidazolyl)methyl]amine; BMPG, N,N-bis[(6-methyl-2-pyridyl)methyl]-glycinate; BIG, N,N-bis[(1-methyl-2-imidazolyl)methyl]glycinate; IPG, N-[(1-methyl-2-imidazolyl)methyl]$\mathrm{N}$-(2-pyridylmethyl)glycinate; PBMPA, N-propanoate- $N, N$-bis-(2-pyridylmethyl)amine.

experimental data. The simulation was performed employing the expression (Lessa et al., 2009):

$$
H=\beta B \cdot g \cdot S+\sum_{j=1}^{2} S \cdot A_{M n} \cdot I_{M n}-g_{n} \beta_{n} B \cdot I_{M n}
$$

with the following $g$ and $A(\mathrm{Mn})$ matrices: $g_{\mathrm{x}}=2.0014$, $g_{\mathrm{y}}=2.0030, g_{\mathrm{z}}=1.9865, A[\mathrm{Mn}(\mathrm{III})]_{1 \mathrm{x}}=136.3 \times 10^{-4} \mathrm{~cm}^{-1}$, $A[\mathrm{Mn}(\mathrm{III})]_{1 \mathrm{y}}=155.5 \times 10^{-4} \mathrm{~cm}^{-1}, A[\mathrm{Mn}(\mathrm{III})]_{1 \mathrm{z}}=103.4$ $\times 10^{-4} \mathrm{~cm}^{-1}, \quad A[\mathrm{Mn}(\mathrm{IV})]_{2 \mathrm{x}}=75.3 \times 10^{-4} \mathrm{~cm}^{-1}$, $A[\mathrm{Mn}(\mathrm{IV})]_{2 \mathrm{y}}=68.6 \times 10^{-4} \mathrm{~cm}^{-1}, A[\mathrm{Mn}(\mathrm{IV})]_{2 \mathrm{z}}=77.4 \times$ $10^{-4} \mathrm{~cm}^{-1}$. These spin Hamiltonian parameters are similar to those for other $\mathrm{Mn}(\mathrm{III})-(\mu-\mathrm{O})-\mathrm{Mn}(\mathrm{IV})$ species reported previously [Mn(III): $S=2, \operatorname{Mn}(\mathrm{IV}): S=3 / 2$, ground state $S=1 / 2$; (Horner et al., 1999)].

As a control, we performed a reaction between a $\mathrm{KO}_{2}$ solution (DMSO) and $\mathrm{Mn}(\mathrm{Cl})_{2} \cdot 4 \mathrm{H}_{2} \mathrm{O}$. In this case, a different behavior was observed when compared to 1 . The signal associated with $\mathrm{Mn}$ (II) disappeared, suggesting that it underwent oxidation. Furthermore, the signal of the superoxide radical remained visible, indicating that $\mathrm{MnCl}_{2}$ did not promote the disproportionation of all superoxide molecules present in solution. On the other hand, compound 1 extinguished the EPR signal associated with the superoxide radical (see Figure ESI13).

Thus, using EPR spectroscopy we could demonstrate that in DMSO, compound $\mathbf{1}$ can decompose the superoxide anion, whose reaction pathway involves the formation of a dimanganese high-valent $\mathrm{Mn}$ (III)-oxo-Mn(IV) species, which is stable for at least $1 \mathrm{~h}$ (Figure 5D). 


\section{Catalase (CAT) Activity}

Bacterial catalases from organisms such as Lactobacillus plantarum, Thermus thermophiles, or Thermoleophilum album (Whittaker, 2012) possess a dinuclear manganese cluster in their active sites. However, we also demonstrated that the mononuclear compounds $\mathbf{2}$ and $\mathbf{3}$ (Figure 1) have catalase activity (Lessa et al., 2009; Ribeiro et al., 2015). Since $\mathbf{1}$ in the solid state and in acetonitrile contains a dimanganese center, but forms a mononuclear complex in DMSO and $\mathrm{H}_{2} \mathrm{O}$, it is plausible to assume that it may show CAT activity as well. We thus investigated the $\mathrm{H}_{2} \mathrm{O}_{2}$ disproportionation promoted by 1 under three different conditions. Firstly, the reaction was investigated in distilled water, but no activity was observed. Secondly, the reaction was performed in a buffered solution (phosphate buffer, $0.05 \mathrm{~mol} \mathrm{dm}^{-3}, \mathrm{pH} 7.8$ ), but again, no activity was observed. This behavior differs significantly from that observed for compounds $\mathbf{2}$ and $\mathbf{3}$, which show CAT activity

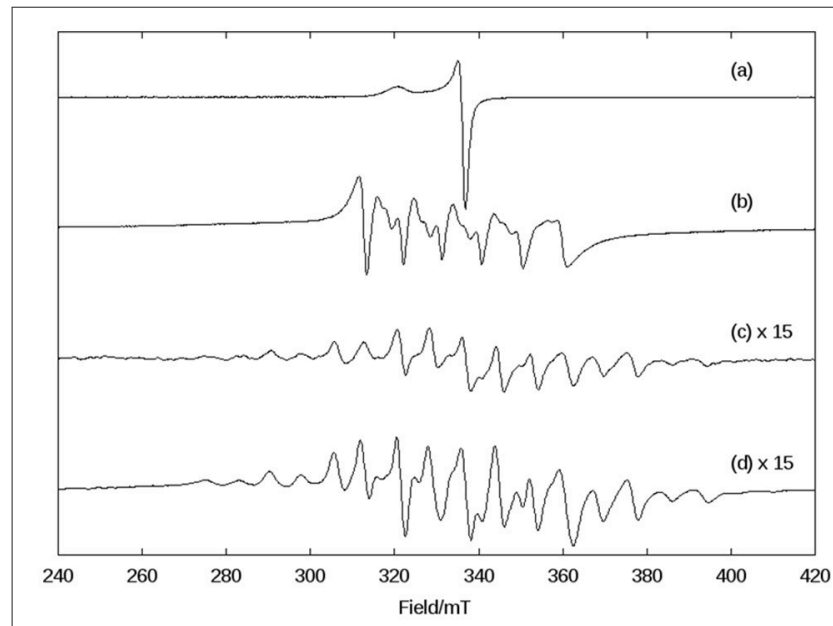

FIGURE $\mathbf{5}$ | X-band CW EPR spectra in DMSO at $140 \mathrm{~K}$ of (A) superoxide $\left(\mathrm{KO}_{2}\right)$, (B) complex $\mathbf{1}$ in dry DMSO, (C) the complex $\mathbf{1}$ immediately after the reaction with superoxide, and (D) the complex $\mathbf{1}, 1 \mathrm{~h}$ after the reaction with superoxide. in pure water as well as buffered solutions (Lessa et al., 2009; Ribeiro et al., 2015). Thirdly, the assay was carried out with piperazine $\left(0.1 \mathrm{~mol} \mathrm{dm}^{-3}, \mathrm{pH}=9.73\right)$ in an aqueous solution and bubbles were produced immediately after the addition of $\mathrm{H}_{2} \mathrm{O}_{2}$. Therefore, kinetic measurements were conducted in the presence of piperazine. The time course of $\mathrm{O}_{2}$ production at 25 ${ }^{\circ} \mathrm{C}$ in the presence of piperazine and at different concentrations of $\mathrm{H}_{2} \mathrm{O}_{2}$ is illustrated in Figure 6. The data were analyzed by a fit to the Michaelis-Menten equation. A similar study was performed by measuring the consumption of $\mathrm{H}_{2} \mathrm{O}_{2}$ by UV-Vis (see Figure ESI14). Relevant parameters are summarized in Table 4, together with corresponding data for other manganese compounds for comparison.

The data presented in Table 4 reveal that the kinetic rates obtained for $\mathbf{1}$ are lower when $\mathrm{O}_{2}$ production is measured than when the consumption of $\mathrm{H}_{2} \mathrm{O}_{2}$ is recorded. This observation suggests that in the UV-Vis experiment, the change in the reading at $240 \mathrm{~nm}$ related to the $\mathrm{H}_{2} \mathrm{O}_{2}$ molecule may be influenced by changes in the absorption of $\mathbf{1}$ at this wavelength. Therefore, the UV-Vis method may not be suitable to evaluate the decomposition rate of $\mathrm{H}_{2} \mathrm{O}_{2}$ when in the presence of molecules that show intense absorption in a comparable wavelength range. Hence, we consider the kinetic parameters obtained with the Clark electrode as more reliable.

The kinetic data show that $\mathbf{1}$ is less active than other dinuclear manganese complexes containing tripodal ligands (tpa, bpia, $\mathrm{L}_{1^{-}}$$\mathrm{L}_{5}$ ). This may be explained by the presence of piperazine, which can compete with $\mathrm{H}_{2} \mathrm{O}_{2}$ by the manganese coordination site. Furthermore, the presence of water has been considered as an inhibitor, too, as exemplified by the compound $\left[\mathrm{Mn}_{2}^{\mathrm{II}}(\mathrm{tpa})_{2}(\mu\right.$ $\left.\mathrm{Cl})_{2}\right]^{2+}$, whose $k_{\text {cat }}$ decreased around 50 times when the reaction was perfomed in $\mathrm{CH}_{3} \mathrm{CN} / \mathrm{H}_{2} \mathrm{O}$ instead of anhydrous $\mathrm{CH}_{3} \mathrm{CN}$. Thus, 1 shows a $k_{\text {cat }}$ comparable to that of $\left[\mathrm{Mn}_{2}^{\mathrm{II}}(\mathrm{tpa})_{2}(\mu-\right.$ $\left.\mathrm{Cl})_{2}\right]^{2+}$.

In an attempt to gain insight into the role of piperazine in the catalytic process, we investigated the interactions between complex 1 and piperazine with different techniques. In Figure 7 the electronic spectrum of $\mathbf{1}$ dissolved in water is shown as a function of an increasing amount of piperazine. Piperazine
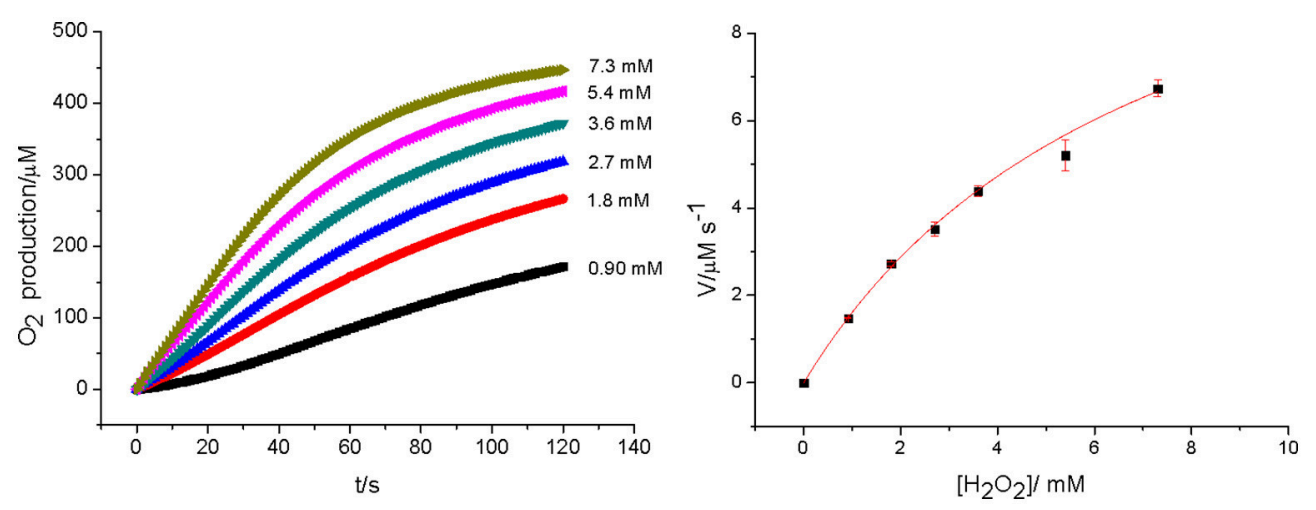

FIGURE 6 | Rates of $\mathrm{O}_{2}$ production at [1] $=2.27 \times 10^{-5} \mathrm{~mol} \mathrm{dm}-3$ and different concentration of $\mathrm{H}_{2} \mathrm{O}_{2}$ (left). The dependence of the rate on substrate concentration, together with a fit to the Michaelis-Menten equation (right). 
TABLE 4 | Kinetic parameters of reported manganese catalase mimetics containing tripodal amine ligands and the natural enzyme.

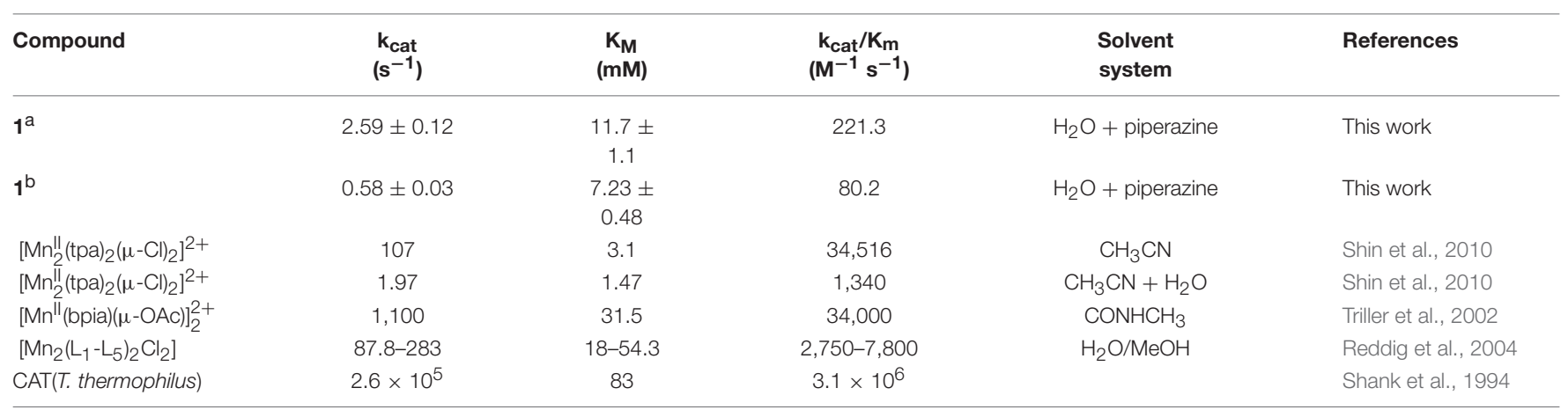

${ }^{a}$ Evaluated by UV-Vis spectroscopy by following $\mathrm{H}_{2} \mathrm{O}_{2}$ consuption.

${ }^{b}$ Measured by electrochemical $\mathrm{O}_{2}$ detection.

Tpa, (tris(2-pycolyl)amine); bpia, bis-(picolyl)(N-methylimidazol-2-yl)amine); L1- $L_{5}$, derivatives of 2-\{[bis(pyridin-2-ylmethyl)amino]methyl\}phenol.

alone does not have any electronic transitions above $300 \mathrm{~nm}$. However, two new distinct transitions were observed when this reagent was added to a solution containing complex 1 . The first transition (shoulder) at $459 \mathrm{~nm}$, associated with a LMCT in complex 1 (vide supra), gained intensity and was red-shifted to $\sim 500 \mathrm{~nm}$. The increase in the intensity of this phenolate $\rightarrow \mathrm{Mn}(\mathrm{III}) \mathrm{LMCT}$ as a function of piperazine concentration suggests that $\mathrm{Mn}(\mathrm{II})$ is undergoing oxidation. A second relevant band appears as a shoulder around $390 \mathrm{~nm}$ and is ascribed to an oxo $\mathrm{Mn}(\mathrm{III}) /(\mathrm{IV})$ transition (Lessa et al., 2009). The driving force for the oxidative process may be linked to either the direct coordination of piperazine to the manganese ion or the deprotonation of the coordinating alcohol group from the ligand (which is protonated as seen in the molecular structure solved by $x$-ray diffraction). The spectral changes observed in Figure 7 also reveal the existence of two consecutive reactions. The band at $500 \mathrm{~nm}$ increases faster than the shoulder around $390 \mathrm{~nm}$, supporting the hypothesis that the first step involves the oxidation induced by piperazine, resulting in an intermediate that reacts with $\mathrm{O}_{2}$. The final species contains a $\mathrm{Mn}(\mathrm{III})$-oxo$\mathrm{Mn}(\mathrm{IV})$ core, as evidenced by ESI-MS and EPR results (see below).

The interaction between piperazine and complex $\mathbf{1}$ was also investigated using ESI-(+)-MS spectrometry. Figure 8 shows the spectra of the pure compound (A) and in the presence of piperazine (B).

The peak assignment of $\mathbf{1}$ was discussed above. In the presence of piperazine the base peak is still at $\mathrm{m} / \mathrm{z} 307$. However, some new species appear, including those at $m / z$ 390, 445 (see Figures ESI15-16) and 734. Of particular relevance is the peak at $m / z 734$, which is absent in the spectrum of $\mathbf{1}$. The calculated and experimental isotopic patterns for this peak are shown in Figure 9. The best simulation (position and intensity) was obtained by assuming the presence of two overlapping species: [(BPCINOL)Mn(III)-( $\mu$-O)-Mn(IV)(BPClNOL) $]^{+}$with $m / z 734$ and $\left[\mathrm{Mn}_{2}(\mathrm{III})(\mathrm{L})_{2}(\mathrm{OH})\right]^{+}$with $\mathrm{m} / z$ 735. The last signal was also observed in the mass spectrum of $\mathbf{1}$ (see above) while the signal at $m / z 734$ is a new species formed in the reaction between $\mathbf{1}$ and piperazine. Thus, in agreement with the UV-Vis spectral data (Figure 7), mass spectrometry supports a mechanism whereby

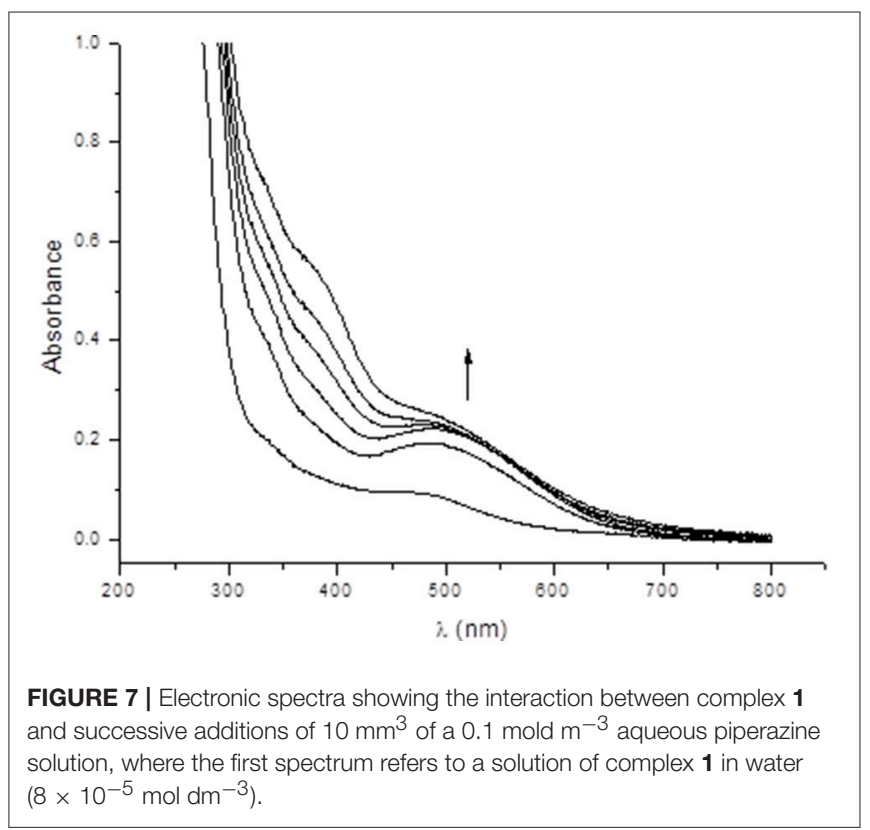

piperazine induces the oxidation of $\mathbf{1}$ to a high-valent $\mathrm{Mn}(\mathrm{III})$ ( $\mu$-O)-Mn(IV) species with $m / z 734$.

The complex formed upon mixing $\mathbf{1}$, piperazine and $\mathrm{H}_{2} \mathrm{O}_{2}$ was also probed by EPR spectroscopy. As discussed above, when 1 is exposed to $\mathrm{H}_{2} \mathrm{O}_{2}$ no oxygen production is observed. Not surprisingly, thus, the EPR spectrum of $\mathbf{1}$ in $\mathrm{CH}_{3} \mathrm{CN}$ and in the presence of $\mathrm{H}_{2} \mathrm{O}_{2}$ is virtually identical to that of the complex alone (i.e., Figure 3, bottom). However, when piperazine is added to $\mathbf{1}$, an immediate change occurs that is consistent with the formation of a species containing a $\mathrm{Mn}(\mathrm{III})-(\mu-\mathrm{O})-\mathrm{Mn}(\mathrm{IV})$ center (Figure 10A); the relevant EPR spectrum has a 16-line feature that is typical of mixed-valent $\mathrm{Mn}$ (III) Mn(IV)- $\mu$-oxobridged species (Horner et al., 1999; Dubois et al., 2008; Jiang et al., 2009; Mitić et al., 2009) supporting the data observed by UV-Vis and ESI-MS. The experimental spectrum could be simulated (see ESI, Figure ESI17) using the same equation and parameters employed in the simulation of the spectrum 


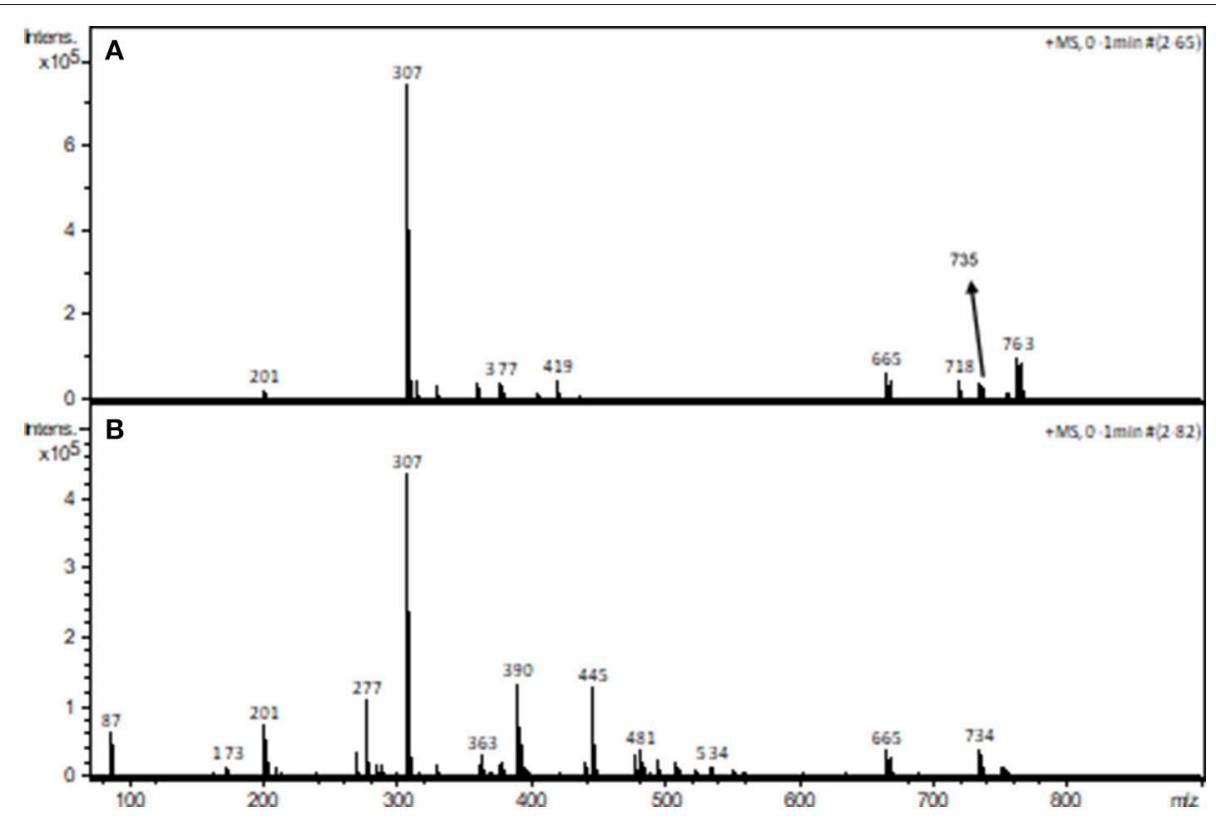

FIGURE 8 | ESI-(+)-MS spectra of complex $\mathbf{1}$ in the absence (A) and in the presence (B) of piperazine in $\mathrm{CH}_{3} \mathrm{CN} / \mathrm{H}_{2} \mathrm{O}$.

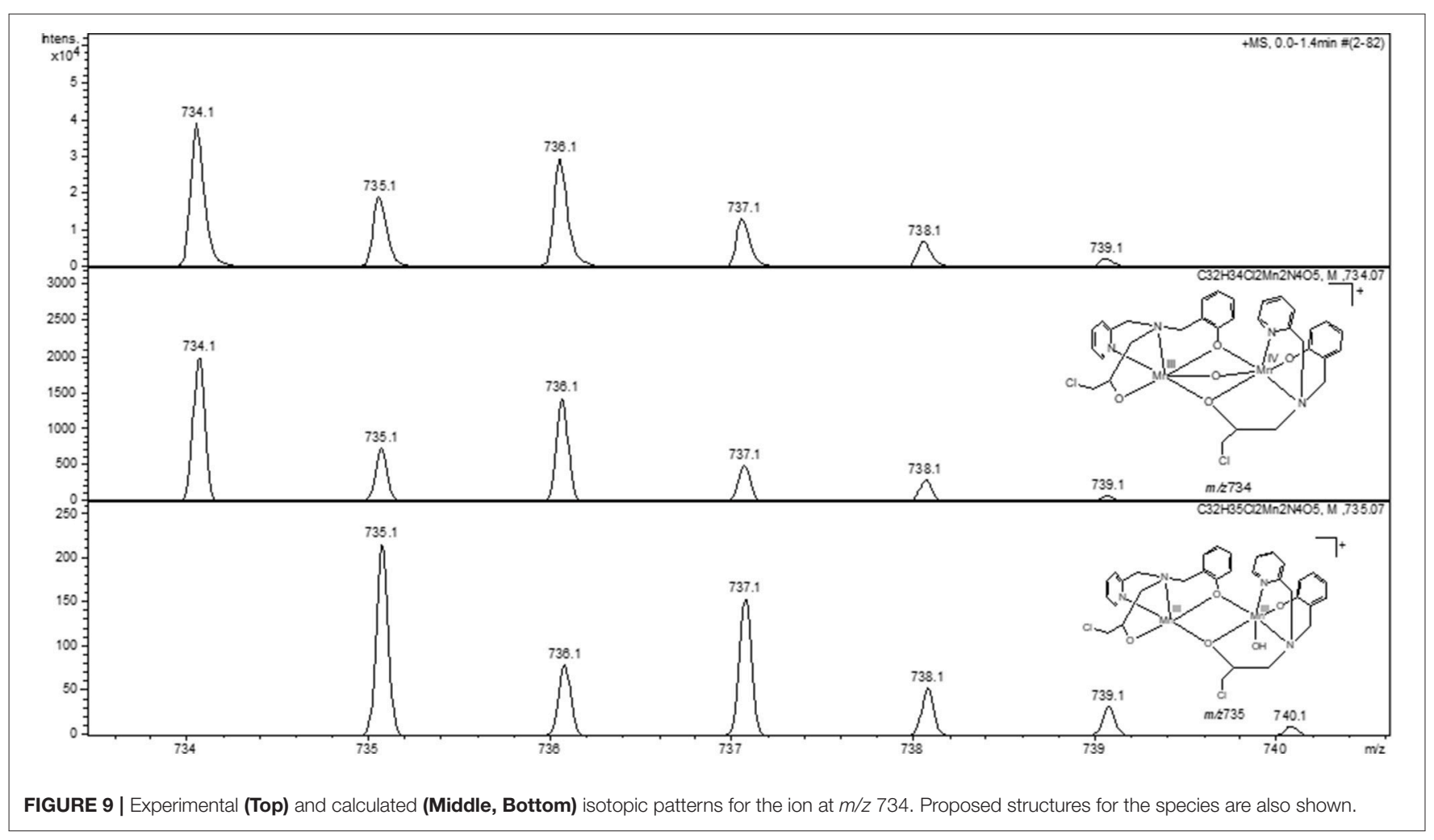

obtained for the reaction between 1 and superoxide (Figures 5, ESI12).

Upon the addition of $\mathrm{H}_{2} \mathrm{O}_{2}$ the spectrum of $\mathrm{Mn}(\mathrm{III})-(\mu-\mathrm{O})-$ $\mathrm{Mn}(\mathrm{IV})$ changes with the loss of some resonances (Figure 10B). Now, at least 10 lines are observed, which suggests the formation of a new chemical species. We tentatively assign this new intermediate as a $\mathrm{Mn}(\mathrm{II}) \mathrm{Mn}(\mathrm{III})$ species, since this compound type has been described as presenting a 12 line spectrum (Larson et al., 1992; Gelasco et al., 1997; Mitić et al., 2009; Smith et al., 2009). 


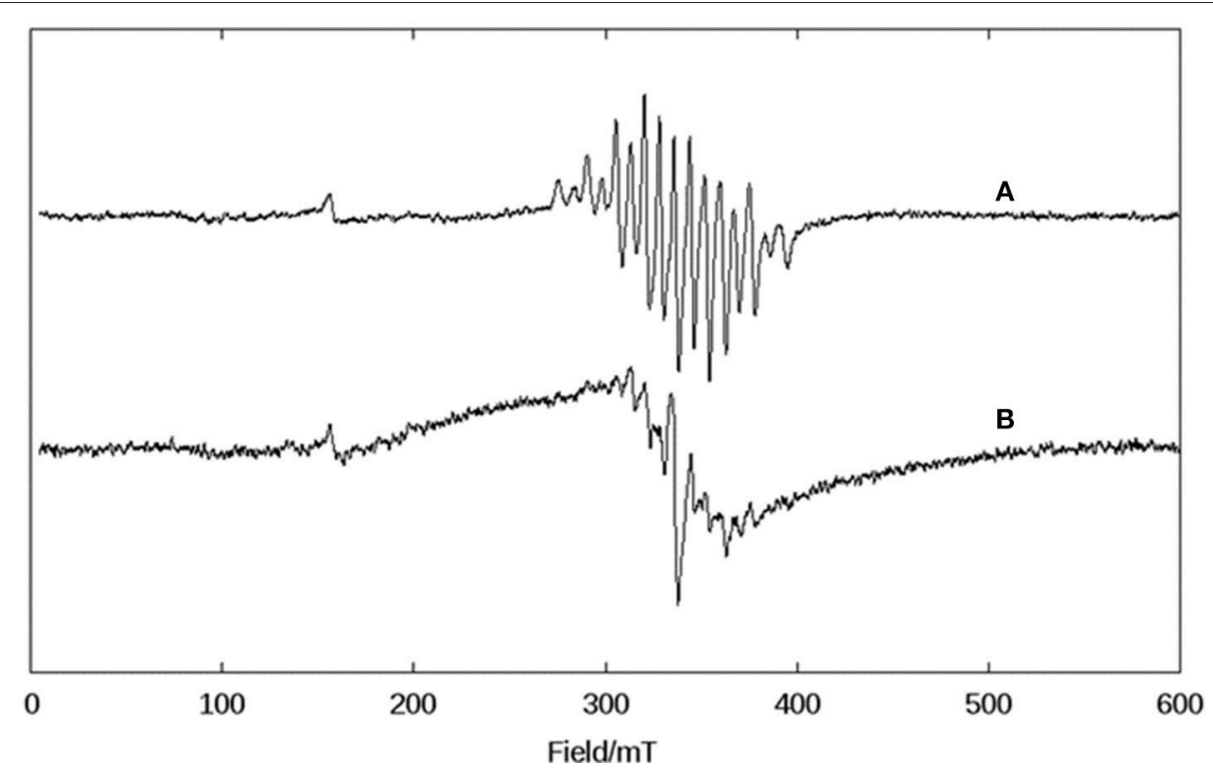

FIGURE 10 |X-band CW EPR spectra of $\mathbf{1}$ in $\mathrm{CH}_{3} \mathrm{CN}$ at $140 \mathrm{~K}$. (A) After the addition of piperazine and (B) after the addition of $\mathrm{H}_{2} \mathrm{O}_{2}$ to a solution containing the complex and piperazine.

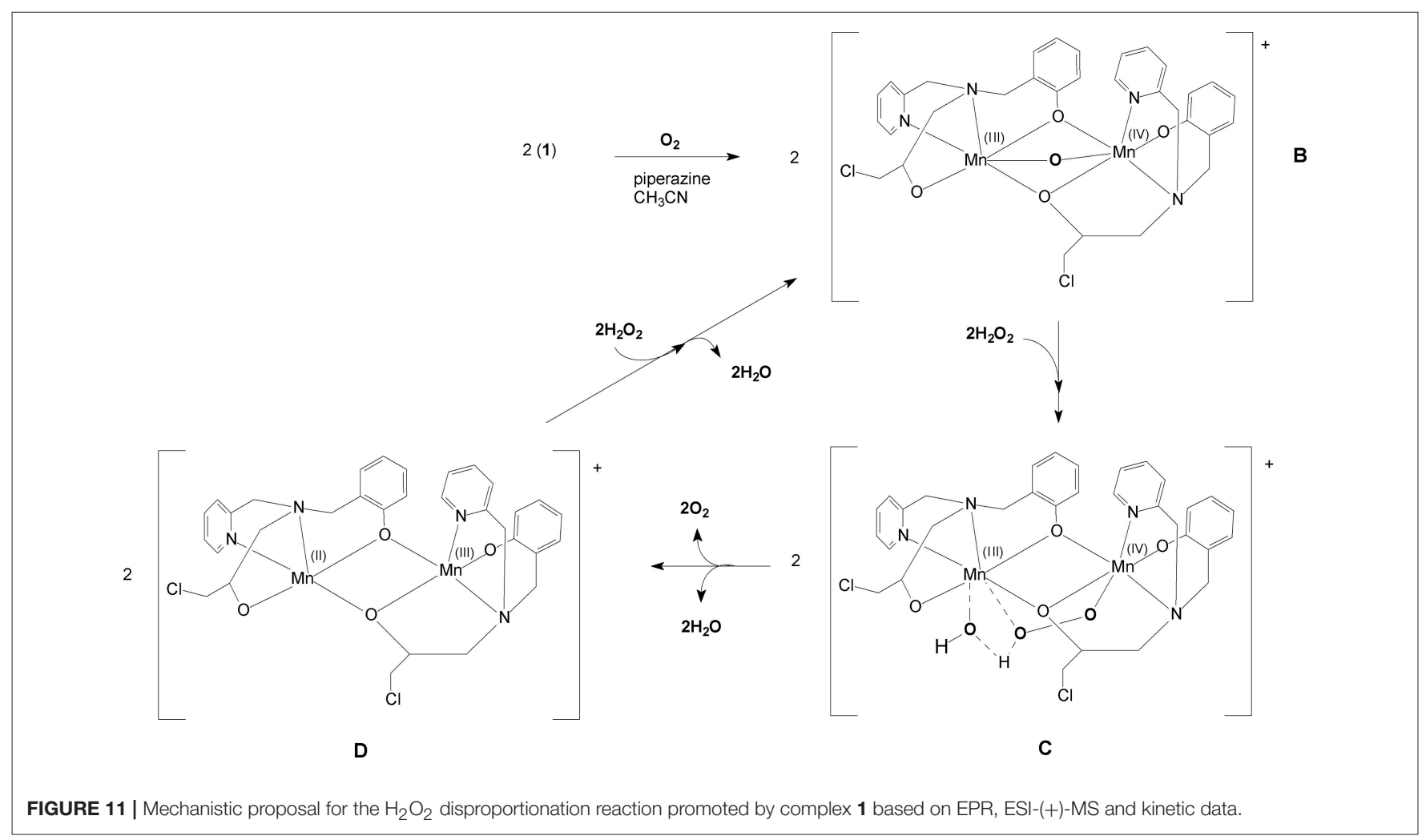

Previously, we have reported an investigation of the CAT activity of complex 2 (Figure 1). Similar to complex 1, a $\mathrm{Mn}(\mathrm{III})-\mathrm{Mn}(\mathrm{IV})$ intermediate was observed by EPR (Lessa et al., 2009). In the present study the Mn(III)Mn(IV) compound is formed after the interaction of a mixed-valent $\mathrm{Mn}(\mathrm{II}) \mathrm{Mn}(\mathrm{III})$ species with piperazine under aerobic conditions.
In contrast, for 2 the formation of a $\mathrm{Mn}(\mathrm{III}) \mathrm{Mn}$ (IV) species was shown to be due to the reaction between a homovalent $\mathrm{Mn}(\mathrm{II})$ complex and $\mathrm{H}_{2} \mathrm{O}_{2}$. Another difference is that for $\mathbf{1}$, only one $\mu$-oxo bridge is proposed to be present, while for 2 , two $\mu$-oxo bridges connect the metal ions. 
It has been shown that the presence of a base (e.g., imidazole, trimethylamine) increases the CAT activity of synthetic compounds and it has been proposed that this increase is associated with the deprotonation of the $\mathrm{H}_{2} \mathrm{O}_{2}$ molecule (Devereux et al., 2002; Grau et al., 2014; Kose et al., 2015). While piperazine is a base it is also a chelator, and hence it could promote CAT reactivity using either property. However, our combined data strongly support the interpretation that piperazine induces changes in the oxidation state and in the coordination environment of the manganese centers in complex 1. A plausible pathway is by promoting the deprotonation of the alcohol function, which changes the Lewis acidity of the $\mathrm{Mn}(\mathrm{II})$, leading to its oxidation in the presence of $\mathrm{O}_{2}$ to generate the $\mathrm{Mn}$ (III)-oxo- $\mathrm{Mn}$ (IV) species. In order to substantiate this hypothesis, we performed a test reaction between 1 and $\mathrm{H}_{2} \mathrm{O}_{2}$, but using triethylamine instead of piperazine (see ESI Figure ESI18). The result revealed a similar catalase activity, suggesting that both piperazine and triethylamine act as a base. EPR studies of the interaction between $\mathbf{1}$ and triethylamine revelead the formation of a $\mathrm{Mn}$ (III)-oxo-Mn(IV) unit, since a 16-line EPR spectrum was observed (Figure ESI19), confirming that both bases (piperazine, triethylamine) induce the formation of the same intermediate.

\section{Mechanistic Proposals}

The evaluation of the $\mathrm{IC}_{50}$ has shown that $\mathbf{1}$ is able to prevent NBT reduction in the presence of superoxide anions (Table 3). Furthermore, we have demonstrated that $\mathbf{1}$ interacts directly with this ROS in DMSO, promoting its decomposition, as seen by the disappearance of the superoxide radical signal (Figure 5). As a consequence of the reaction, the characteristic 6-line EPR spectrum from a $\mathrm{Mn}$ (II) complex was transformed into a 16line one, which is typical of a $\mathrm{Mn}(\mathrm{III}) \mathrm{Mn}(\mathrm{IV})$-coupled species containing a $\mu$-oxo bridge (Larson et al., 1992; Gelasco et al., 1997; Lessa et al., 2009; Mitić et al., 2009; Smith et al., 2009). Additionally, the EPR spectra of $\mathbf{1}$ in water and in DMSO are equivalent, indicating that the dinuclear structure is broken in solution, generating $\mathrm{Mn}$ (II) and $\mathrm{Mn}$ (III) species. Therefore, it is plausible to assume that the chemical species present in the water solution employed in the catalytic study is similar to the one present in the DMSO solution employed for the superoxide dismutation study monitored via EPR. Thus, we propose that in the initial step of the reaction the superoxide anion reacts with two mononuclear $\mathrm{Mn}(\mathrm{II})$ species (observed by EPR), resulting in a peroxo complex (Equation 1) containing a $\mathrm{Mn}$ (II) Mn(III) center, which subsequently is further oxidized to a high-valent $\mathrm{Mn}(\mathrm{III}) \mathrm{Mn}(\mathrm{IV})$ species (Equation 2). The two electrons involved in this process are necessary to reduce the peroxide species to water, leading to the formation of a $\mu$-oxo bridge which was detected by EPR (Equation 2). These two steps are similar to those proposed for the compounds $\left[\mathrm{Mn}(\mathrm{BIG})\left(\mathrm{H}_{2} \mathrm{O}\right)_{2}\right]^{+}$and $[\mathrm{Mn}(\mathrm{IPG})(\mathrm{MeOH})]$ (Policar et al., 2001). The reaction of this high-valent species with another superoxide generates molecular oxygen with the concomitant formation of a $\mathrm{Mn}$ (III)-oxoMn(III) species (Equation 3). This homo-valent species may be re-oxidized by the reaction with another superoxide molecule, forming $\mathrm{H}_{2} \mathrm{O}_{2}$ and the high-valent $\mathrm{Mn}$ (III)Mn(IV) species in the process (Equation 4), which then enters the reaction again at the step described by Equation (3).

$$
\begin{aligned}
& 2 \mathrm{Mn}(\mathrm{II})+\mathrm{O}_{2}^{-} \rightarrow \mathrm{Mn}(\mathrm{II}) \mathrm{Mn}(\mathrm{III})-\text { peroxide } \\
& \mathrm{Mn}(\mathrm{II}) \mathrm{Mn}(\mathrm{III})-\text { peroxide } \rightarrow \mathrm{Mn}(\mathrm{III})-\text { oxo--Mn(IV) }+\mathrm{H}_{2} \mathrm{O} \\
& \mathrm{Mn}(\mathrm{III})-\text { oxo-Mn(IV) }+\mathrm{O}_{2}^{-} \rightarrow \mathrm{Mn}(\mathrm{III})-\text { oxo-Mn(III) }+\mathrm{O}_{2} \\
& \mathrm{Mn}(\mathrm{III})-\text { oxo-Mn(III) }+\mathrm{O}_{2}{ }^{-} \rightarrow \mathrm{Mn}(\mathrm{III})-\text { oxo-Mn(IV) }+ \text { peroxide }
\end{aligned}
$$

Commonly SOD mimetics are already in the active form to promote the reduction of superoxide to peroxide and molecular oxygen. For example, Mn-porphyrins and Mn-salen compounds show SOD like activity in which the oxidation state changes between III/II (Shin et al., 2010; Signorella et al., 2018). For such systems the catalytic process usually involves a step for the oxidation of superoxide, thus forming molecular oxygen, and another step for the reduction of superoxide, resulting in the formation of hydrogen peroxide (ping-pong mechanism). On the other hand, complexes containing tripodal amine ligands sometimes need to be activated to promote the disproportionation of ROS (Lessa et al., 2009; Signorella et al., 2018) as observed for the compounds $\left[\mathrm{Mn}(\mathrm{BIG})\left(\mathrm{H}_{2} \mathrm{O}\right)_{2}\right]^{+}$and [Mn(IPG)(MeOH)] (Policar et al., 2001), which, after reacting with superoxide, are transformed into the dinuclear species $\mathrm{Mn}^{\mathrm{III}}-(\mu-\mathrm{O})_{2}-\mathrm{Mn}^{\mathrm{IV}}$. The same behavior was described for the mononuclear compounds $\left[\mathrm{Mn}^{\mathrm{II}}(\mathrm{N} 4 \mathrm{py})(\mathrm{OTf})\right](\mathrm{OTf})$ (Leto et al., 2013).

A proposed model for the CAT mechanism employed by $\mathbf{1}$ is shown in Figure 11. When $\mathbf{1}$ is placed in contact with piperazine, an oxidation process occurs, transforming the system to $\mathrm{Mn}(\mathrm{III})-(\mu-\mathrm{O})-\mathrm{Mn}(\mathrm{IV})$. Thus, we propose that $\mathbf{1}$ is transformed to $\mathrm{B}$, the mixed-valent $\mu$-oxo bridged species that was observed by UV-Vis, ESI-MS and EPR. The next step $(\mathrm{B} \rightarrow \mathrm{C}$ in Figure 11) occurs after the addition of $\mathrm{H}_{2} \mathrm{O}_{2}$. The formation of a new $\mathrm{Mn}(\mathrm{III}) \mathrm{Mn}(\mathrm{IV})$ complex is proposed, in which a hydroperoxide molecule displaces the $\mu$ oxo group. This interpretation would explain why the 16-line EPR feature disappears in the presence of $\mathrm{H}_{2} \mathrm{O}_{2}$ (Figure 10). In this unstable arrangement, the peroxide molecule may transfer two electrons to the binuclear $\mathrm{Mn}(\mathrm{III}) \mathrm{Mn}(\mathrm{IV})$ cluster, resulting in the release of molecular oxygen and water and the generation of a $\mathrm{Mn}(\mathrm{II}) \mathrm{Mn}$ (III) center ( $\mathrm{D}$ in Figure 11). Further reaction with $\mathrm{H}_{2} \mathrm{O}_{2}$ results in the formation of the $\mathrm{Mn}(\mathrm{III})$-oxo-Mn(IV) species again (B in Figure 11) and release of $\mathrm{H}_{2} \mathrm{O}$.

The proposed mechanism for the CAT activity presented by $\mathbf{1}$ is significantly different from that proposed for $\mathbf{2}$. 1 needs to be transformed into the active species by piperazine, forming a $\mathrm{Mn}(\mathrm{III})-(\mu-\mathrm{O})-\mathrm{Mn}(\mathrm{IV})$. In contrast, 2 reacts directly with $\mathrm{H}_{2} \mathrm{O}_{2}$ and a $\mathrm{Mn}(\mathrm{III})-(\mu-\mathrm{O})_{2}-\mathrm{Mn}(\mathrm{IV})$ intermediate is formed.

\section{CONCLUSIONS}

In this study we have reported the synthesis and characterization of an unusual mixed-valent manganese compound which forms a polymeric linear chain in the solid state. It consists of 
$\mathrm{Mn}(\mathrm{II}) \mathrm{Mn}$ (III) subunits, in which the manganese ions are connected by a phenoxide and an alkoxide bridge (Figures 1, 2). The subunits are linked via chloro bridges. In the solid state, 1 shows two distinct magnetic interactions. An antiferromagnetic one $\left[J=-5.224(13) \mathrm{cm}^{-1}\right]$ is observed between the monomers (through chloro bridges) and a ferromagnetic coupling $\left[J=+0.076(13) \mathrm{cm}^{-1}\right]$ is observed in the monomeric unit (via the alkoxide/phenoxide bridges). The latter interaction supports the attribution that the signal observed in the EPR spectrum at $g$ around 7 is a result of a ferromagnetic coupled $\mathrm{Mn}$ (III)Mn(II) system, and therefore, that the compound remains as a dinuclear center in $\mathrm{CH}_{3} \mathrm{CN}$. In contrast, EPR spectroscopy has revealed that in DMSO and $\mathrm{H}_{2} \mathrm{O}$ solutions the dinuclear structure is broken, leading to monomeric $\mathrm{Mn}$ (II) and $\mathrm{Mn}$ (III) units (Figure 3). Importantly, in aqueous environment, the compound has dual antioxidant activity, i.e., it acts both as a catalase and as superoxide dismutase. For the reaction with superoxide, a $\mathrm{Mn}(\mathrm{III})-(\mu-\mathrm{O})$ $\mathrm{Mn}(\mathrm{IV})$ species was identified as intermediate by EPR. With respect to the catalase activity, we found that the resting $\mathrm{Mn}$ (II)Mn(III) species is active only in presence of a base such as piperazine or trimethylamine. It was shown that piperazine promotes the formation of an active $\mathrm{Mn}(\mathrm{III})-(\mu-\mathrm{O})-\mathrm{Mn}(\mathrm{IV})$. An intermediate of the reaction of this $\mathrm{Mn}(\mathrm{III})-(\mu-\mathrm{O})-\mathrm{Mn}(\mathrm{IV})$ species with $\mathrm{H}_{2} \mathrm{O}_{2}$ could also be detected by EPR, suggesting that the formation of a $\mathrm{Mn}$ (II)Mn(III) species that promote the CAT activity of $\mathbf{1}$, involves a $\mathrm{Mn}^{\mathrm{II}} \mathrm{Mn}^{\mathrm{III}} / \mathrm{Mn}^{\mathrm{III}} \mathrm{Mn}^{\mathrm{IV}}$ redox couple.

\section{AUTHOR'S NOTE}

Catalase activity evaluated by UV-Vis, the comparison of the catalase activity in the presence of piperazine and triethylamine, ESI- $(+)-\mathrm{MS}$ and EPR data are presented as supporting information. Crystallographic data for the structure reported in this paper have been deposited with the Cambridge Crystallographic Data Centre as supplementary publication. Deposition number: 1478947. Copies of the data can be obtained free of charge from the CCDC at www.ccdc.cam.ac.uk.conts/ retrieving.html/ or from the Cambridge Crystallographic Data Centre (CCDC), 12 Union Road, Cambridge CB2 IEZ, UK; fax: 44(0) 1223-336033; e-mail: deposit@ccdc.cam.ac.uk.

\section{REFERENCES}

Allen, R. G., and Tresini, M. (2000). Oxidative stress and gene regulation. Free Radic. Biol. Med. 28, 463-499. doi: 10.1016/S0891-5849(99)00242-7

Antonyuk, S. V., Melik-Adamyan, V. R., Popov, A. N., Lamzin, V. S., Hempstead, P. D., Harrison, P. M., et al. (2000). Three-dimensional structure of the enzyme dimanganese catalase from Thermus thermophilus at 1 A resolution. Crystallogr. Rep. 45, 105-116. doi: 10.1134/1.171145

Barondeau, D. P., Kassmann, C. J., Bruns, C. K., Tainer, J. A., and Getzoff, E. D. (2004). Nickel superoxide dismutase structure and mechanism. Biochemistry 43, 8038-8047. doi: 10.1021/bi0496081

Batinić-Haberle, I., Rebouças, J. S., and Spasojević, I. (2010). Superoxide dismutase mimics: chemistry, pharmacology, and therapeutic potential. Antioxid. Redox Signal. 13, 877-918. doi: 10.1089/ars.2009.2876

\section{AUTHOR CONTRIBUTIONS}

RC, SF, and CP carried out the syntheses, the characterization of the compounds and the kinetics experiments. $\mathrm{JH}, \mathrm{CN}$, and RF carried out the EPR experiments, and the simulations of the data. JR performed the $\mathrm{x}$-ray experiments and the data treatment. $\mathrm{PC}$ and $\mathrm{AR}$ were responsible for the magnetism measurements and data interpretation. GS contributed in the analyses and discussion of kinetic data. $\mathrm{CF}$ and $\mathrm{AH}$ conceived and planned the experiments, supervised the progress of this work, and took the lead in writing the manuscript. All authors discussed the results and contributed to the final manuscript.

\section{FUNDING}

The authors are grateful to financial support received from CAPES (Coordenação de Aperfeiçoamento de Pessoal de Nível Superior-Brazil) through the Program Capes/Probral (88881.143979/2017-01) and the Australian Research Council (ARC; DP150104358). CF acknowledges the funding received from CAPES (BEX 6338/14-3). GS and JH also acknowledge receipt of ARC Future Fellowships (FT120100694 and FT120100421, respectively). AR gratefully acknowledges funding by the Heidelberg Graduate School of Mathematical and Computational Methods for the Sciences (HGS MathComp), founded by DFG grant GSC 220 in the German Universities Excellence Initiative. JR acknowledge CNPq for their fellowships (311142/2017-6).

\section{ACKNOWLEDGMENTS}

We thank Prof. Dr. Jurandi G. de Oliveira from LMGV/CCTA/UENF for providing access to an oxygraph for the evaluation of the CAT activity and also to Laboratório Regional de Difração de Raios X located at Universidade Federal Fluminense by the $\mathrm{x}$-ray experiments.

\section{SUPPLEMENTARY MATERIAL}

The Supplementary Material for this article can be found online at: https://www.frontiersin.org/articles/10.3389/fchem. 2018.00491/full\#supplementary-material

Beers, R. F Jr., and Sizer, I. W. (1952). A spectrophotometric method for measuring the breakdown of hydrogen peroxide by catalase. J. Biol. Chem. 195, 133-140.

Bravo, J., Mate, M. J., Schneider, T., Switala, J., Wilson, K., Loewen, P. C., et al. (1999). Structure of catalase HPII from Escherichia coli at $1.9 \AA$ resolution. PROTEINS: Struct. Funct. Genet. 34, 155-166. doi: 10.1002/(SICI)1097-0134(19990201)34:2

Bull, C., Niederhoffer, E. C., Yoshida, T., and Fee, J. A. (1991). Kinetic studies of superoxide dismutases: properties of the manganese-containing protein from Thermus thermophilus. J. Am. Chem. Soc. 113, 4069-4076. doi: 10.1021/ja00011a003

Coates, C. M., Fiedler, S. R., McCullough, T. L., Albrecht-Schmitt, T. E., Shores, M. P., and Goldsmith, C. R. (2010). Synthesis and characterization of an asymmetric, linear, trinuclear manganese(II) complex. Inorg. Chem. 49, 1481-1486. doi: 10.1021/ic901758s 
Costa, V., and Moradas-Ferreira, P. (2001). Oxidative stress and signal transduction in Saccharomyces cerevisiae: insights into ageing, apoptosis and diseases. Mol. Aspects Med. 22, 217-246. doi: 10.1016/S0098-2997(01)00012-7

Day, B. J. (2007). Catalase and glutathione peroxidase mimics. Biochem. Pharmacol. 77, 285-296. doi: 10.1016/j.bcp.2008.09.029

Devereux, M., McCann, M., Leon, V., McKee, V., and Ball, R. J. (2002). Synthesis and catalytic activity of manganese(II) complexes of heterocyclic carboxylic acids: X-ray crystal structures of $\left[\mathrm{Mn}(\mathrm{pyr})_{2}\right] \mathrm{n},\left[\mathrm{Mn}(\right.$ dipic $\left.)(\text { bipy })_{2}\right] \cdot 4.5 \mathrm{H}_{2} \mathrm{O}$ and $\left[\mathrm{Mn}(\right.$ chedam $)($ bipy) $] \cdot \mathrm{H}_{2} \mathrm{O}$ (pyr=2-pyrazinecarboxylic acid; dipic=pyridine2,6-dicarboxylic acid; chedam =chelidamic acid(4-hydroxypyridine-2,6dicarboxylic acid); bipy=2,2-bipyridine). Polyhedron 21, 1063-1071. doi: 10.1016/S0277-5387(02)00842-2

Doctrow, S. R., Huffman, K., Marcus, C. B., Tocco, G., Malfroy, E., Adinolfi, C. A., et al. (2002). Salen-manganese complexes as catalytic scavengers of hydrogen peroxide and cytoprotective agents: structure-activity relationship studies. J. Med. Chem. 45, 4549-4558. doi: 10.1021/jm020207y

Dubois, L., Pécaut, J., Charlot, M. F., Baffert, C., Collomb, M. N., Deronzier, A., et al. (2008). Carboxylate ligands drastically enhance the rates of oxo exchange and hydrogen peroxide disproportionation by oxo manganese compounds of potential biological significance. Chem. Eur. J. 14, 3013-3025. doi: 10.1002/chem.200701253

Durot, S., Policar, C., Cisnetti, F., Lambert, F., Renault, J. P., Pelosi, G., et al. (2005). Series of Mn complexes based on $N$-centered ligands and superoxide reactivity in an anhydrous medium and SOD-like activity in an aqueous medium correlated to $\mathrm{Mn}^{\mathrm{II}} / \mathrm{Mn}^{\mathrm{III}}$ redox potentials. Eur. J. Inorg. Chem. 3513-3523. doi: 10.1002/ejic.200400835

Eckshtain, M., Zilbermann, I., Mahammed, A., Saltsman, I., Okun, Z., Maimon, E., et al. (2009). Superoxide dismutase activity of corrole metal complexes. Dalton Trans. 14, 7879-7882. doi: 10.1039/b911278b

Fernandes, C., Horn, A. Jr., Vieira-da-Motta, O., de Assis, V. M., Rocha, M. R., Mathias L da, S., et al. (2010). Synthesis, characterization and antibacterial activity of FeIII, CoII, CuII and ZnII complexes probed by transmission electron microscopy. J. Inorg. Biochem. 104, 1214-1223. doi: 10.1016/j.jinorgbio.2010.07.011

Fu, Y., Li, Q., Zhou, Z., Dai, W., Wang, D., Mak, T. C. W., et al. (1996). The first example of a bis-monohelical complex: the crystal and molecular structure of $\left[\mathrm{Mn}_{2}(\mathrm{dmqpy})_{2}\left(\mathrm{H}_{2} \mathrm{O}\right)_{2}(\mu-\mathrm{Cl})\right]\left[\mathrm{ClO}_{4}\right]_{3} \cdot 4 \mathrm{H}_{2} \mathrm{O}$ (dmqpy $=$ 6,6-dimethyl2,2' : 6', $2^{\prime \prime}: 6^{\prime \prime}, 2^{\prime \prime \prime}$ : 6-quinquepyridine). Chem. Commun. 1549-1550. doi: 10.1039/CC9960001549

Gelasco, A., Kirk, M. L., Kampf, J. W., and Pecoraro, V. L. (1997). The $[\mathrm{Mn}(2)(2-\mathrm{OH} s a l p n)(2)](2-,-, 0,+)$ system: synthesis, structure, spectroscopy, and magnetism of the first structurally characterized dinuclear manganese series containing four distinct oxidation states. Inorg. Chem. 36, 1829-1837. doi: 10.1021/ic970140i

Gibson, V. C., McTavish, S., Redshaw, C., Solan, G. A., White, A. J. P., and Williams, D. J. (2003). From monomeric to polymeric manganese complexes bearing bis(imino)pyridine and related ligands. Dalton Trans. 221-226. doi: 10.1039/b207384f

Gomes, C. A., Lube, L. M., Fernandes, C., Franco, R. W. A., Resende, J. A. L. C., Horn, A., et al. (2017). A new system for cyclohexane functionalization employing iron(III) catalysts and trichloroisocyanuric acid. New J. Chem. 41, 11498-11502. doi: 10.1039/C7NJ01164D

Grau, M., Rigodanza, F., White, A. J., Sorarù, A., Carraro, M., Bonchio, M., et al. (2014). Ligand tuning of single-site manganese-based catalytic antioxidants with dual superoxide dismutase and catalase activity. Chem. Commun. 50, 4607-4609. doi: 10.1039/C4CC00758A

Halliwell, B. (2006). Reactive species and antioxidants. Redox biology is a fundamental theme of aerobic life. Plant Physiol. 141, 312-322. doi: $10.1104 /$ pp.106.077073

Hancock, J. T., Desikan, R., and Neill, S. J. (2001). Role of reactive oxygen species in cell signaling pathways. Biochem. Soc. Trans. 29, 345-350. doi: 10.1042/bst0290345

Hänninen, M. M., Välivaara, J., Mota, A. J., Colacio, E., Lloret, F., and Sillanpää, R. (2013). Ferromagnetic dinuclear mixed-valence $\mathrm{Mn}$ (II)/Mn(III) complexes: building blocks for the higher nuclearity complexes. structure, magnetic properties, and density functional theory calculations. Inorg. Chem. 52, 2228-2241. doi: 10.1021/ic302731z
Hirotsu, M., Shimizu, Y., Kuwamura, N., Tanaka, R., Kinoshita, I., Takada, R., et al. (2012). Anion-controlled assembly of four manganese ions: structural, magnetic, and electrochemical properties of tetramanganese complexes stabilized by xanthene-bridged Schiff base ligands. Inorg. Chem. 51, 766-768. doi: $10.1021 /$ ic $202287 \mathrm{k}$

Horn, A., Fernandes, C., Bortoluzzi, A. J., Vugman, N. V., and Herbst, M. H. (2005a). Coordination chemistry of the new ligand 1-(bis-pyridin2-ylmethyl-amino)-3-chloropropan-2-ol (HPCINOL) with copper(II). Xray crystal structure, spectroscopic and electrochemical properties of the complex $[\mathrm{Cu}(\mathrm{HPClNOL})(\mathrm{CH} 3 \mathrm{CN})](\mathrm{ClO} 4) 2$. J. Mol. Struct. 749, 96-102. doi: 10.1016/j.molstruc.2005.03.045

Horn, A., Fim, L., Bortoluzzi, A. J., Szpoganicz, B., and Fernandes, C. (2006a). Solid state and solution characterization of a new dinuclear nickel (II) complex: the search for synthetic models for urease. J. Mol. Struct. 797, 154-164. doi: 10.1016/j.molstruc.2006.03.043

Horn, A., Neves, A., Vencato, I., Drago, V., Zucco, C., Werner, R., et al. (2000). A new dinucleating $\mathrm{N}, \mathrm{O}$ donor ligand $\left(\mathrm{H}_{2} \mathrm{BPClNOL}\right)$ and the structural and magnetic properties of two diiron complexes with the di- $\mu$-Alkoxo Motif. $J$. Braz. Chem. Soc. 11, 7-10. doi: 10.1590/S0103-50532000000100002

Horn, A., Vencato, I., Bortoluzzi, A. J., Drago, V., Novak, M. A., and Neves, A. (2006b). Synthesis, molecular structure and spectroscopic, electrochemical and magnetic properties of a new dinuclear iron complex containing $\mu$-sulfatedi- $\mu$-alkoxo bridges. Evaluating the influence of the sulfate bridge on the physicochemical properties of the di- $\mu$-alkoxo-diiron unit. J. Braz. Chem. Soc. 17, 1584-1593. doi: 10.1590/S0103-50532006000800015

Horn, A., Vencato, I., Bortoluzzi, A. J., Hörner, R., Silva, R. A. N., Szpoganicz, B., et al. (2005b). Synthesis, crystal structure and properties of dinuclear iron(III) complexes containing terminally coordinated phenolate $/ \mathrm{H}_{2} \mathrm{O} / \mathrm{OH}^{-}$groups as models for purple acid phosphatases: efficient hydrolytic DNA cleavage. Inorg. Chim. Acta 358, 339-351. doi: 10.1016/j.ica.2004.09.021

Horner, O., Anxolabéhère-Mallart, E., Charlot, M. F., Tchertanov, L., Guilhem, J., Mattioli, T. A., et al. (1999). A new manganese dinuclear complex with phenolate ligands and a single unsupported oxo bridge. Storage of two positive charges within less than $500 \mathrm{mV}$. relevance to photosynthesis. Inorg. Chem. 38, 1222-1232. doi: 10.1021/ic980832m

Jiang, X., Liu, H., Zheng, B., and Zhang, J. (2009). Coordination modes of bridge carboxylates in dinuclear manganese compounds determine their catalase-like activities. Dalton Trans. 8714-8723. doi: 10.1039/b907687e

Jung, M., and Rentschler, E. (2015). Magnetic and spectroscopic study on a new asymmetric mixed-valence Mn2(II,III) coordination compound. Z. Anorg. Allg. chem. 641, 2277-2281. doi: 10.1002/zaac.201500551

Karsten, P., Neves, A., Bortoluzzi, A. J., Strähle, J., and Maichle-Mössmer, C. (2002). Synthesis, structure and catalase-like activity of a new dinuclear mixed valence $\mathrm{Mn}^{\mathrm{II}} \mathrm{Mn}^{\mathrm{III}}$ complex containing an unsymmetric $\mathrm{N}_{5} \mathrm{O}_{2}$ donor ligand. Inorg. Chem. Commun. 5, 434-438. doi: 10.1016/S1387-7003(02)00435-5

Kerfeld, C. A., Yoshida, S., Tran, K. T., Yeates, T. O., Cascio, D., Bottin, H., et al. (2003). The $1.6 \AA$ resolution structure of Fe-superoxide dismutase from the thermophilic cyanobacterium Thermosynechococcus elongatus. J. Biol. Inorg. Chem. 8, 707-714. doi: 10.1007/s00775-003-0469-0

Kose, M., Goring, P., Lucas, P., and Mckee, V. (2015). Mono-, di- and tri-nuclear manganese(II) complexes derived from a quinquedentate ligand: Superoxide dismutase and catalase mimetic studies. Inorg. Chim. Acta 435, 232-238. doi: 10.1016/j.ica.2015.07.010

Krause, L., Herbst-Irmer, R., Sheldrick, G. M., and Stalke, D. (2015). Comparison of silver and molybdenum microfocus X-ray sources for single-crystal structure determination. J. Appl. Crystallogr. 48, 3-10. doi: 10.1107/S1600576714022985

Kupershmidt, L., Okun, Z., Amit, T., Mandel, S., Saltsman, I., Mahammed, A., et al. (2010). Metallocorroles as cytoprotective agents against oxidative and nitrative stress in cellular models of neurodegeneration. J. Neurochem. 113, 363-373. doi: $10.1111 /$ j.1471-4159.2010.06619.x

Lane, N. (2003). A unifying view of ageing and disease: the double-agent theory. $J$. Theor. Biol. 225, 531-540. doi: 10.1016/S0022-5193(03)00304-7

Larson, E., Haddy, A., Kirk, M. L., Sands, R. H., Hatfield, W. E., and Pecoraro, V. L. (1992). Asymmetric mixed-valent complex $\{[\mathrm{Mn}(2-\mathrm{OH}-3,5-$ $\mathrm{Cl}_{2}$-SALPN) $]_{2}$ (THF) $\} \mathrm{ClO}_{4}$ shows a temperature-dependent interconversion between $\mathrm{g}=2$ multiline and low-field EPR signals. J. Am. Chem. Soc. 114, 6263-6265. doi: 10.1021/ja00041a065 
Ledesma, G. N., Eury, H., Anxolabéhère-Mallart, E., Hureau, C., and Signorella, S. R. (2015). A new mononuclear manganese(III) complex of an unsymmetrical hexadentate $\mathrm{N} 3 \mathrm{O} 3$ ligand exhibiting superoxide dismutase and catalase-like activity: synthesis, characterization, properties and kinetics studies. J. Inorg. Biochem. 146, 69-76. doi: 10.1016/j.jinorgbio.2015.02.012

Lessa, J. A., Horn, A., Bull, E. S., Rocha, M. R., Benassi, M., Catharino, R. R., et al. (2009). Catalase vs peroxidase activity of a manganese(II) compound: identification of a $\mathrm{Mn}(\mathrm{III})-(\mu-\mathrm{O})_{2}-\mathrm{Mn}(\mathrm{IV})$ reaction intermediate by electrospray ionization mass spectrometry and electron paramagnetic resonance spectroscopy. Inorg. Chem. 48, 4569-4579. doi: 10.1021/ic801969c

Lessa, J. A., Horn, A., Pinheiro, C. B., Farah, L. L., Eberlin, M. N., Benassi, M., et al. (2007). Synthesis, solid-state and in-solution structures of a new seven coordinated manganese(II) complex via X-ray diffraction and electrospray ionization mass spectrometry. Inorg. Chem. Commun. 10, 863-866. doi: 10.1016/j.inoche.2007.04.001

Leto, D. F., Chattopadhyay, S., Day, V. W., and Jackson, T. A. (2013). Reaction landscape of a pentadentate N5-ligated $\mathrm{Mn}$ (II) complex with $\mathrm{O}_{2}{ }^{-}$and $\mathrm{H}_{2} \mathrm{O}_{2}$ includes conversion of a peroxomanganese(III) adduct to a bis( $\mu$-oxo)dimanganese(III,IV) species. Dalton Trans. 42, 13014-13025. doi: $10.1039 / \mathrm{c} 3 \mathrm{dt} 51277 \mathrm{k}$

Lu, J., and Holmgren, A. (2009). Selenoproteins. J. Biol. Chem. 284, 723-727. doi: $10.1074 /$ jbc.R800045200

Ludwig, M. L., Metzger, A. L., and Pattridge, K. A. (1991). Stallings WC manganese superoxide dismutase from Thermus thermophilus. A structural model refined at $1.8 \mathrm{~A}$ resolution. J. Mol. Biol. 219, 335-358. doi: 10.1016/0022-2836(91)90569-R

Magherusan, A. M., Zhou, A., Farquhar, E. R., García-Melchor, M., Twamley, B., Que, L. Jr., et al. (2018). Mimicking class I b Mn2-ribonucleotide reductase: a MnII2 complex and its reaction with superoxide. Angew. Chem. Int. Ed. Engl. 57, 918-922. doi: 10.1002/anie.201709806

Mahammed, A., and Gross, Z. (2011). The importance of developing metal complexes with pronounced catalase-like activity. Catal. Sci. Technol. 1, 535-540. doi: 10.1039/clcy00063b

McCord, J. M., and Edeas, M. A. (2005). SOD, oxidative stress and human pathologies: a brief history and a future vision. Biomed. Pharmacother. 59, 139-142. doi: 10.1016/j.biopha.2005. 03.005

Mitić, N., Noble, C. J., Gahan, L. R., Hanson, G. R., and Schenk, G. (2009). Metalion mutagenesis: conversion of a purple acid phosphatase from sweet potato to a neutral phosphatase with the formation of an unprecedented catalytically competent $\mathrm{Mn}(\mathrm{II}) \mathrm{Mn}(\mathrm{II})$ active site. J. Am. Chem. Soc. 131, 8173-8179. doi: $10.1021 /$ ja $900797 \mathrm{u}$

Mitić, N., Saleh, L., Schenk, G., Bollinger, J. M. Jr., and Solomon, E. I. (2003). Rapidfreeze-quench magnetic circular dichroism of intermediate $\mathrm{X}$ in ribonucleotide reductase: new structural insight. J. Am. Chem. Soc. 125, 11200-11201. doi: $10.1021 / \mathrm{ja} 036556 \mathrm{e}$

Morano, K. A., Grant, C. M., and Moye-Rowley, W. S. (2012). The response to heat shock and oxidative stress in Saccharomyces cerevisiae. Genetics 190, 1157-1195. doi: 10.1534/genetics.111.128033

Naiya, S., Biswas, S., Drew, M. G., Gómez-García, C. J., and Ghosh, A. (2012). A ferromagnetic methoxido-bridged $\mathrm{Mn}(\mathrm{III})$ dimer and a spincanted metamagnetic $\mu$ (1,3)-azido-bridged chain. Inorg. Chem. 51, 5332-5341. doi: $10.1021 /$ ic $300274 \mathrm{n}$

O'Connor, M., Kellett, A., McCann, M., Rosair, G., McNamara, M., Howe, O., et al. (2012). Copper(II) complexes of salicylic acid combining superoxide dismutase mimetic properties with DNA binding and cleaving capabilities display promising chemotherapeutic potential with fast acting in vitro cytotoxicity against cisplatin sensitive and resistant cancer cell lines. J. Med. Chem. 55, 1957-1968. doi: 10.1021/jm201041d

Orchard, A. F. (2003). Magnetochemistry. New York, NY: Oxford University Press Inc.

Pap, J. S., Kripli, B., Bors, I., Bogáth, D., Giorgi, M., Kaizer, J., et al. (2012). Transition metal complexes bearing flexible N3 or N3O donor ligands: Reactivity toward superoxide radical anion and hydrogen peroxide. J. Inorg. Biochem. 117, 60-70. doi: 10.1016/j.jinorgbio.2012. 08.012

Pei, Y., Kahn, O., Sletten, J., Renard, J. P., Georges, R., Gianduzzo, J. C., et al. (1988). Structure and magnetism of the first alternating bimetallic chain compound $\mathrm{MnCu}(\mathrm{obp})\left(\mathrm{H}_{2} \mathrm{O}\right)_{3} \cdot$ cntdot. $\mathrm{H}_{2} \mathrm{O}$ [obp = oxamidobis(propionato)]. Inorg. Chem. 27, 47-53. doi: 10.1021/ic00274a011

Policar, C., Durot, S., Lambert, F., Cesario, M., Ramiandrasoa, F., and Morgenstern-Badarau, I. (2001). New $\mathrm{Mn}^{\mathrm{II}}$ complexes with an N/O coordination sphere from tripodal $N$-centered ligands - characterization from solid state to solution and reaction with superoxide in nonaqueous and aqueous media. Eur. J. Inorg. Chem. 1807-1818. doi: 10.1002/1099-0682(200107)2001:7

Ramilo, C. A., Leveque, V., Guan, Y., Lepocki, J. R., Tainer, J. A., Nick, H. S., et al. (1999). Interrupting the hydrogen bond network at the active site of human manganese superoxide dismutase. J. Biol. Chem. 274, 27711-27740. doi: $10.1074 / j b c .274 .39 .27711$

Rane, S. Y., Khan, E. M., Thube, D. R., Padhye, S. B., Date, S. K., and Bakare, P. P. (2000). A ferro- and antiferro-magnetically coupled binuclear manganese (II,III) complex of an orthofunctionalised para-naphthoquinone: Synthesis and characterization by thermogravimetric, thermochromic, cyclic voltammetric, magnetic and EPR studies. Ind. J. Chem. 39, 1117-1123.

Reddig, N., Pursche, D., Kloskowski, M., Slinn, C., Baldeau, S. M., and Rompel, A. (2004). Tuning the catalase activity of dinuclear manganese complexes by utilizing different substituted tripodal ligands. Eur. J. Inorg. Chem. 4, 879-887. doi: $10.1002 /$ ejic.200300157

Ribeiro, J. P., Segundo, M. A., Reis, S., and Lima, J. L. (2009). Spectrophotometric FIA methods for determination of hydrogen peroxide: application to evaluation of scavenging capacity. Talanta 79, 1169-1176. doi: $10.1016 /$ j.talanta.2009.02.039

Ribeiro, T. P., Fernandes, C., Melo, K. V., Ferreira, S. S., Lessa, J. A., Franco, R. W., et al. (2015). Iron, copper, and manganese complexes with in vitro superoxide dismutase and/or catalase activities that keep Saccharomyces cerevisiae cells alive under severe oxidative stress. Free Radic. Biol. Med. 80 67-76. doi: 10.1016/j.freeradbiomed.2014.12.005

SAINT (2015). Bruker APEX3 and SAINT. Madison, WI: Bruker AXS Inc.

Sano, Y., Weitz, A. C., Ziller, J. W., Hendrich, M. P., and Borovik, A. S. (2013). Unsymmetrical bimetallic complexes with $\mathrm{M}^{\mathrm{II}}-(\mu-\mathrm{OH})-\mathrm{MIII}$ cores $\left(\mathrm{M}^{\mathrm{II}} \mathrm{M}^{\mathrm{III}}=\mathrm{Fe}^{\mathrm{II}} \mathrm{Fe}^{\mathrm{III}}, \mathrm{Mn}^{\mathrm{II}} \mathrm{Fe}^{\mathrm{III}}, \mathrm{Mn}^{\mathrm{II}} \mathrm{Mn}^{\mathrm{III}}\right)$ : structural, magnetic, and redox properties. Inorg. Chem. 52, 10229-10231. doi: 10.1021/ic401561k

Schake, A. R., Schmitt, E. A., Conti, A. J., Streib, W. E., Huffman, J. C., Hendrickson, D. N., et al. (1991). Preparation and properties of mononuclear and ferromagnetically coupled dinuclear manganese complexes with 2, 2'biphenoxide. Inorg. Chem. 30, 3192-3199. doi: 10.1021/ic00016a017

Shank, M., Barynin, V., and Dismukes, G. C. (1994). Protein coordination to manganese determines the high catalytic rate of dimanganese catalases. Comparison to functional catalase mimics. Biochemistry 33, 15433-15436. doi: 10.1021/bi00255a025

Sheldrick, G. M. (2015). Crystal structure refinement with SHELXL. Acta Crystallograph. Sect. C 71, 3-8. doi: 10.1107/S2053229614024218

Shin, B. K., Kim, M., and Han, J. (2010). Hydrogen peroxide disproportionation by the $\left[\mathrm{TPA}_{2} \mathrm{Mn}_{2}(\mu-\mathrm{Cl})_{2}\right]^{2+}$ complex. Polyhedron 29, 2560-2568. doi: 10.1016/j.poly.2010.05.029

Signorella, S., Palopoli, C., and Ledesma, G. (2018). Rationally designed mimics of antioxidant manganoenzymes: role of structural features in the quest for catalysts with catalase and superoxide dismutase activity. Coord. Chem. Rev. 365, 75-102. doi: 10.1016/j.ccr.2018.03.005

Singh, R., Haukka, M., McKenzie, C. J., and Nordlander, E. (2015). High turnover catalase activity of a mixed-valence $\mathrm{Mn}^{\mathrm{II}} \mathrm{Mn}^{\mathrm{III}}$ complex with terminal carboxylate donors. Eur. J. Inorg. Chem. 21, 3485-3492. doi: $10.1002 /$ ejic. 201500468

Smith, S. J., Riley, M. J., Noble, C. J., Hanson, G. R., Stranger, R., Jayaratne, V., et al. (2009). Structural and catalytic characterization of a heterovalent $\mathrm{Mn}(\mathrm{II}) \mathrm{Mn}$ (III) complex that mimics purple acid phosphatases. Inorg. Chem. 48, 10036-10048. doi: 10.1021/ic9005086

Suksrichavalit, T., Prachayasittikul, S., Piacham, T., Isarankura-Na-Ayudhya, C., Nantasenamat, C., and Prachayasittikul, V. (2008). Copper complexes of nicotinic-aromatic carboxylic acids as superoxide dismutase mimetics. Molecules 13, 3040-3056. doi: 10.3390/molecules 13123040

Tainer, J. A., Getzoff, E. D., Beem, K. M., Richardson, J. S., and Richardson, D. C. (1982). Determination and analysis of the 2 A-structure of copper, zinc superoxide dismutase. J. Mol. Biol. 160, 181-217. doi: 10.1016/0022-2836(82)90174-7 
Tovmasyan, A., Maia, C. G., Weitner, T., Carballal, S., Sampaio, R. S., Lieb, D., et al. (2015). A comprehensive evaluation of catalase-like activity of different classes of redox-active therapeutics. Free Radic. Biol. Med. 86, 308-321. doi: 10.1016/j.freeradbiomed.2015.05.018

Triller, M. U., Hsieh, W-Y, Pecoraro, V. L., Rompel, A., and Krebs, B. (2002). Preparation of highly efficient manganese catalase mimics. Inorg. Chem. 41, 5544-5554. doi: 10.1021/ic025897a

Valentine, J. S., Miksztal, A. R., and Sawyer, D. T. (1984). Methods for the study of superoxide chemistry in nonaqueous solutions. Methods Enzymol. 105, 71-81. doi: 10.1016/S0076-6879(84)05010-2

Valentine, J. S., Tatsuno, Y., and Nappa, M. (1977). Superoxotetraphenylporphinatozinc(1-). J. Am. Chem. Soc. 99, 3522-3523.

Valko, M., Leibfritz, D., Moncol, J., Cronin, M. T., Mazur, M., and Telser, J. (2007). Free radicals and antioxidants in normal physiological functions and human disease. Int. J. Biochem. Cell Biol. 39, 44-84. doi: 10.1016/j.biocel.2006.07.001

Weekley, C. M., Kenkel, I., Lippert, R., Wei, S., Lieb, D., Cranwell, T., et al. (2017). Cellular fates of manganese(II) pentaazamacrocyclic superoxide dismutase (SOD) mimetics: fluorescently labeled MnSOD mimetics, X-ray absorption spectroscopy, and X-ray fluorescence microscopy studies. Inorg. Chem. 56, 6076-6093. doi: 10.1021/acs.inorgchem.6b03073

Weser, U., Schubotz, L. M., and Lengfelder, E. (1981). Imidazole-bridged copper complexes as $\mathrm{Cu}_{2} \mathrm{Zn}_{2-}$ superoxide dismutase models. J. Molec. Catal. 13, 249-261. doi: 10.1016/0304-5102(81)85025-0
Whittaker, J. W. (2012). Non-heme manganese catalase - the 'other' catalase. Arch. Biochem. Biophys. 525, 111-120. doi: 10.1016/j.abb.2011.12.008

Wittick, L. M., Murray, K. S., Moubaraki, B., Batten, S. R., Spiccia, L., and Berry, K. J. (2004). Synthesis, structure and magnetism of new single molecule magnets composed of $\mathrm{Mn}_{2}^{\mathrm{II}} \mathrm{Mn}_{2}^{\mathrm{III}}$ alkoxo-carboxylate bridged clusters capped by triethanolamine ligands. Dalton Trans. 1003-1011. doi: 10.1039/b312672b

Zou, L. F., Zhao, L., Guo, Y. N., Tang, J., Wang, Q. L., and Li, Y. H. (2012). N1,N5-Bis(3-ethoxysalicylidene)-di-imino-3-azapentane-based $\mathrm{Mn}^{3+}, \mathrm{Co}^{3+}$ and $\mathrm{Cu}^{2+}$ complexes: Synthesis, coordination behavior and magnetic properties. Inorg. Chim. Acta 382, 65-71. doi: 10.1016/j.ica.2011. 10.019

Conflict of Interest Statement: The authors declare that the research was conducted in the absence of any commercial or financial relationships that could be construed as a potential conflict of interest.

Copyright () 2018 Costa, Ferreira, Pereira, Harmer, Noble, Schenk, Franco, Resende, Comba, Roberts, Fernandes and Horn. This is an open-access article distributed under the terms of the Creative Commons Attribution License (CC BY). The use, distribution or reproduction in other forums is permitted, provided the original author(s) and the copyright owner(s) are credited and that the original publication in this journal is cited, in accordance with accepted academic practice. No use, distribution or reproduction is permitted which does not comply with these terms. 